\title{
Dynamic Characteristics Analysis of the Coupled Lateral-Torsional Vibration with Spur Gear System
}

\author{
Shihua Zhou, Zhaohui Ren, Guiqiu Song, and Bangchun Wen \\ School of Mechanical Engineering \& Automation, Northeastern University, Shenyang 110819, China \\ Correspondence should be addressed to Zhaohui Ren; zhhren@mail.neu.edu.cn
}

Received 3 June 2015; Revised 9 September 2015; Accepted 14 September 2015

Academic Editor: Alessandro Corsini

Copyright ( 2015 Shihua Zhou et al. This is an open access article distributed under the Creative Commons Attribution License, which permits unrestricted use, distribution, and reproduction in any medium, provided the original work is properly cited.

\begin{abstract}
A sixteen-degree-of-freedom (16-DOF) lumped parameter dynamic model taking into account the gravity, eccentricity, bearing clearance, transmission error, and coupled lateral-torsional vibration is established. Based on the dynamical equation, the dynamic behaviors of the spur gear rotor bearing system are investigated by using Runge-Kutta method. The research focuses on the effect of rotational speed, eccentricity, and bearing clearance and nonlinear response of the coupled multibody dynamics is presented by vibration waveform, spectrum, and 3D frequency spectrum. The results show that the rotational frequency of the driven gear appears in the driving gear, and the dynamic characteristics of gears have obvious differences due to the effects of the gear assembly and the coupled lateral-torsional vibration. The bearing has its own resonance frequency, and the effect of the variable stiffness frequency of the bearings should be avoided during the system design. The results presented in this paper show an analysis of the coupled lateral-torsional vibration of the spur gear system. The study may contribute to a further understanding of the dynamic characteristics of such a spur gear rotor bearing system.
\end{abstract}

\section{Introduction}

It is known that the gear system is widely used in power and motion transmission device of modern rotating machineries, which are designed for high rotational speed, safety, and efficiency. The excitation and work environment have a very important effect on the entire machine. In order to understand dynamic behaviors of gear drives, it is very important to establish exact coupled lateral-torsional dynamic model of geared rotor system. In addition, due to the effect of gear meshing, the gear system presents different vibration characteristics to compare with simplified rotor system. One of the main features of gear model is that it has the coupled lateral-torsional vibration between the driving gear and driven gear. If the gear drive system does not consider the coupled lateral-torsional vibration, the calculation accuracy reduces and some important dynamic characteristics may be lost (torsional excitation may excite the lateral response and coupled lateral-torsional vibration causes new frequency component). In recent years, many researchers have made a great contribution to study dynamic characteristics of spur gear systems by, respectively, applying experimental methods, numerical simulation, and analytical methods [1$6]$. Lin $[1,2]$ established a torsional vibration model of gear rotor system and studied the parameter influence of meshing force, dynamic load, and tip relief. Raghothama and Narayanan [3] investigated the periodic motions of a nonlinear gear rotor bearing system by the incremental harmonic balance method (IHBM), and the periodic solutions and subharmonic solutions were obtained. Lund [4] and Iida et al. [5] proposed a dynamic model with coupled vibration of gear system, in which the lateral-torsional motion was considered. They provided effective method for dynamic design of the transmission system. Kahraman and Singh [6] studied the nonlinear dynamic characteristics of spur gear system with the HBM. In order to further study the nonlinear characteristics of gear transmission system, Kahraman and Singh [7] deduced the nonlinear dynamic equation of spur gear rotor system and the influences of various parameters were studied and they analyzed the nonlinear dynamic response of spur gear system with HBM and Runge-Kutta method. Due to the effect of time-varying mesh stiffness, 
Kahraman [8, 9] sequentially analyzed the effect of the gear rotor bearing system with the backlash and the time-varying meshing stiffness and carried out a detailed analysis to the nonlinear system. Sun et al. [10] analyzed the rotational and flexural vibration of a spur gear system considering the shafts, gears, and bearing. In addition, the influence of gear eccentric mass and tooth contact frictional force was taken into account on the system vibrations. The model of coupled bending and torsional nonlinear vibration was established for high-speed geared rotor bearing system by [11-13]. Kim et al. [14] proposed a new dynamic model for the gear set, considering translational motion. In addition, the pressure angle and the contact ratio were regarded as time-varying variables, and some dynamic response differences between the new and previous models were demonstrated. Based on both single- and multidegree freedom models, Velex and Ajmi [15] established a formal link between dynamic tooth loads and quasi-static transmission errors in helical gear sets. Bahk and Parker [16] developed the nonlinear dynamics of planetary gears by numerical and analytical methods over the meaningful mesh frequency ranges. The analytical solutions gave insight into the nonlinear dynamics such as jump phenomena, subharmonic resonance, and the impact. Faggioni et al. [17] presented a global optimization method focused on gear vibration reduction by means of profile modifications, which reduced the vibrations over a wide range of operating conditions and the optimum reliability was estimated using a Monte Carlo simulation. Litvin et al. [18] attacked the problem of gear noise using three-dimensional models (helical, hypoid, and worm gears), and two-dimensional parabolic modifications were optimal for noise reduction. Omar et al. [19] investigated dynamic response of a spur gear pair using a finite element/contact mechanics model, which offered significant advantages for dynamic gear analyses. Ma [20, 21] established a finite element model of a cracked gear coupled rotor system in a one-stage reduction gearbox and the effects of crack depth, width, initial position, crack propagation direction on gear mesh stiffness, fault features in time domain and frequency domain, and statistical indicators were investigated. ChangJian and Chen [22] presented a series of investigations into the dynamic behaviors of gear-bearing system with nonlinear suspension, nonlinear oil-film force, and nonlinear gear mesh force. The results provided an understanding of the operating conditions, where the undesirable dynamic motion took place in a gear-bearing system. Shen $[23,24]$ used the IHBM to analyze the nonlinear dynamics of a spur gear pair with arbitrary precision. In addition, the influence of the damping ratio and the excitation amplitude on frequency response curves was researched. Yang et al. [25] proposed a nonlinear time-varying dynamic model for right-angle gear pair system by considering both backlash and asymmetric mesh effects. And on this basis, a set of parametric studies were performed to determine quantitatively the effects of the variation and asymmetry in mesh stiffness and directional rotation radius on the gear dynamic responses. Wu et al. [26] studied the effects of tooth crack on the vibration response of a one-stage gearbox with spur gears. The growth in a tooth crack was reflected in the total mesh stiffness of the gear system. Walha et al. [27] adopted a gear impact theory based on the work and used lumped stiffness and damping representations to model the supporting bearing. Russo et al. [28] performed a lot of experiments to quantify the effect of lubrication on the idle gear rattle response of helical pairs inside an automotive gearbox. Han et al. [29] developed a new multibody dynamic model to predict the mesh force during gear rattle. The results show good agreement with the predictions of a single-degreeof-freedom theoretical model.

It can be seen from the previous references that the most of existing gear transmission system ignores the nonlinear support, shaft elastic deformation, and the gravity of the spur system. Hence, the gear rotor bearing system comprehensively including the eccentricity, bearing clearance, and other factors with a nonlinear dynamic model of coupled lateral-torsional vibration is rare. In order to obtain detailed analysis and master dynamic characteristics of spur gear rotor bearing system, it is necessary to establish precise dynamic model of the gear system. A requirement for reliable spur gear system design calculations is sufficient insight into the dynamics of the entire wind turbine drive train. To study the dynamic behaviors of the spur gear system which can indicate the meshing relations and the nonlinear characteristics, it is necessary to establish accurate mechanics model and suitable mechanism relation model. In this paper, considering the complex nonlinear factors, an analytical model is proposed by lumped parameter method, which can study the vibration characteristics of gear systematically. The vibration responses of the gear system and stability analysis are investigated in various cases. Moreover, a comprehensive physical parametric study is accomplished to evaluate the effect of various dynamic parameters such as rotational speed, eccentricity, and bearing clearance.

The structure of the paper is as follows. After this introduction, the dynamic model and vibration differential equation of gear rotor bearing system are presented in Section 2. In Section 3, the influence of the parameters on the characteristics and level of vibrations are studied. And the vibration responses of the coupled lateral-torsional system are analyzed. Finally, conclusions are drawn in Section 4.

\section{Mathematical Model and Equations of Motion}

2.1. Dynamic Model of Spur Gear Rotor Bearing System. A 16-DOF lumped parameter dynamic model considering the coupled lateral-torsional vibration is developed to study the dynamic characteristics of the spur gear rotor bearing system. The physical model and dynamic model of the gear system are shown in Figures 1 and 2, respectively. In Figure 1, The fixed coordinate $A_{i}-x_{i} y_{i} z_{i}(i=1,2)$ is established at $A_{i}$, which is the center ideal of the driving and driven gears. $B_{i}-x_{i} y_{i} z_{i}(i=1-4)$ represents the center ideal of bearings. In Figure 2, $O_{1}\left(x_{1}, y_{1}\right)$ and $O_{2}\left(x_{2}, y_{2}\right)$ are the rotational centers of the spur geared rotors, respectively. $G_{1}\left(x_{g 1}, y_{g 1}\right)$ and $G_{2}\left(x_{g 2}, y_{g 2}\right)$ represent centers of mass of spur gears. $m_{1}$ and $m_{2}$ indicate the equivalent mass of the driving and driven gears. $J_{i}(i=1,2, d, l)$ represent the rotational inertia of the 


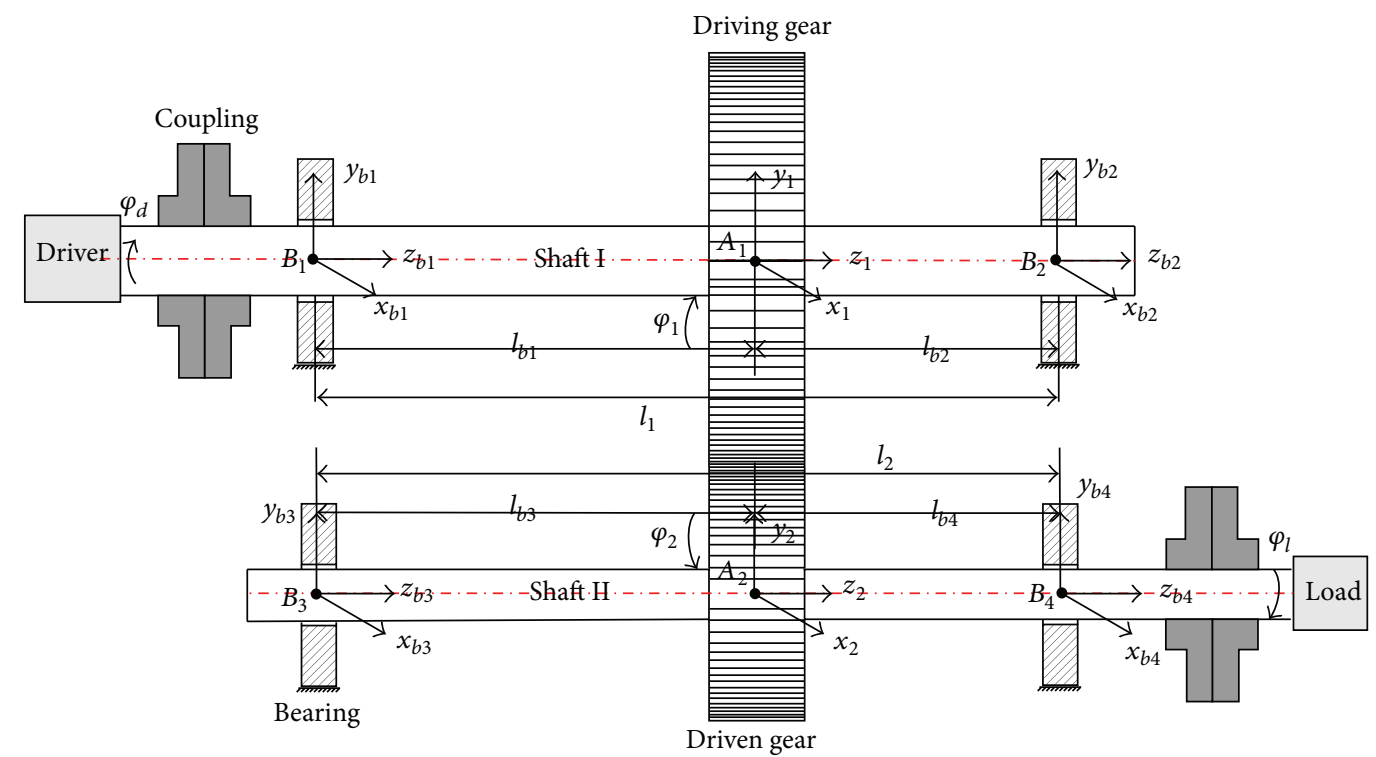

FIgURe 1: Physical model of spur gear rotor bearing system.
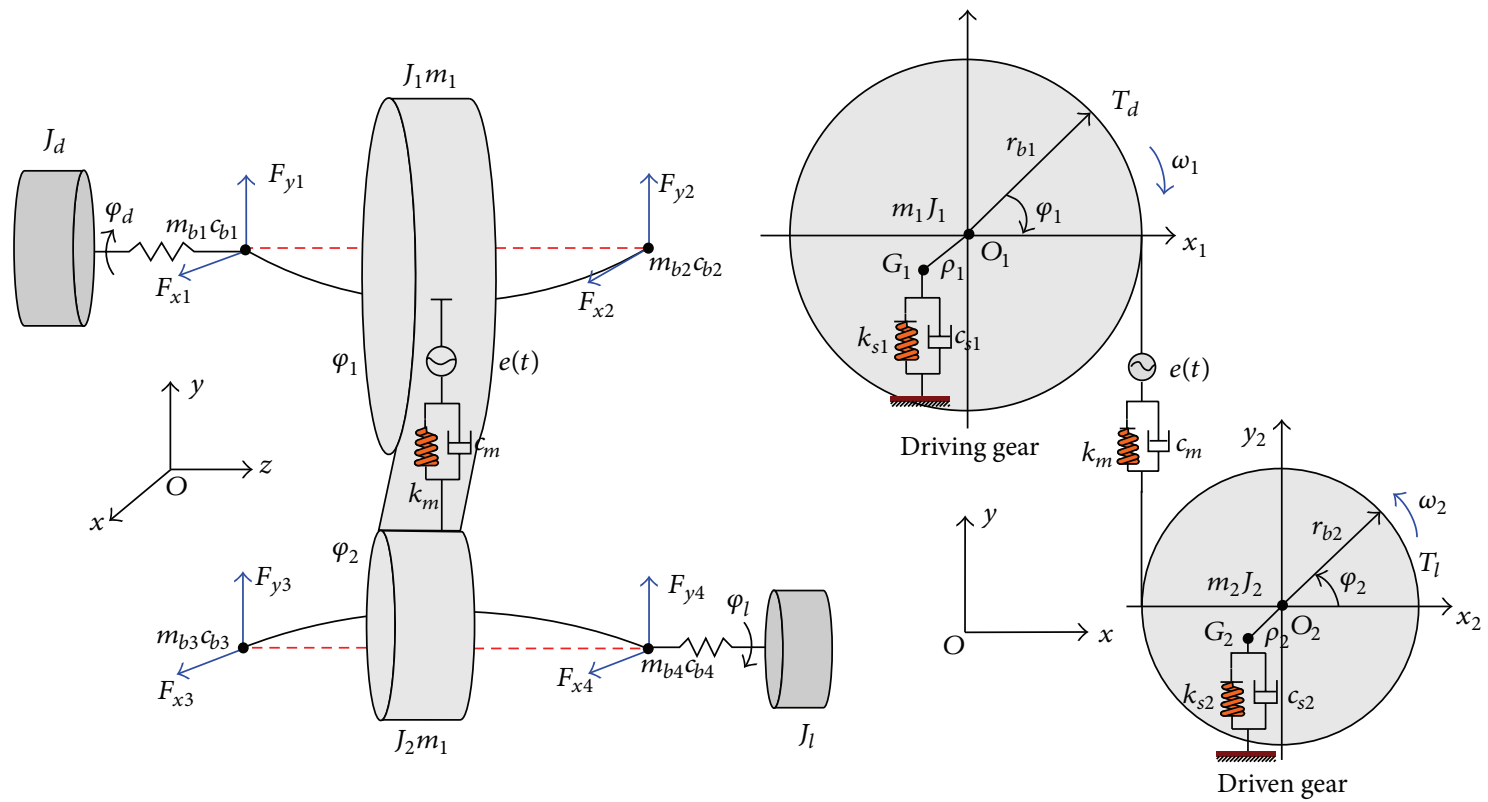

Figure 2: Dynamic model of spur gear rotor bearing system.

gears and input/output terminal, respectively. In addition, $m_{b i}$ $(i=1-4)$ is the equivalent masses of the bearings. $\rho_{1}$ and $\rho_{2}$ are eccentricities of the spur gears. $r_{b 1}$ and $r_{b 2}$ represent the base radius of driving and driven gears.

In order to keep the model formulations at a manageable level, it is assumed that the meshing line direction is $y$ direction in coordinate system in Figure 2. The torsional angular displacements of input/output and driving and driven gears are assumed to result from a constant angular velocity term $\omega_{i} t(i=1,2)$ plus a small variation displacement $\theta_{i}(t)(i=d, 1,2, l)$ due to vibrations originating from the flexibility of the gear meshing. Therefore, the angle displacements $\varphi_{i}(t)$ of the gears and input/output can be expressed:

$$
\begin{aligned}
& \varphi_{d}=\omega_{1} t+\theta_{d}, \\
& \varphi_{1}=\omega_{1} t+\theta_{1}, \\
& \varphi_{2}=\omega_{2} t+\theta_{2}, \\
& \varphi_{l}=\omega_{2} t+\theta_{l},
\end{aligned}
$$

where $\omega_{1}$ and $\omega_{2}$ are the constant angular velocity components of the driving and driven gears. 


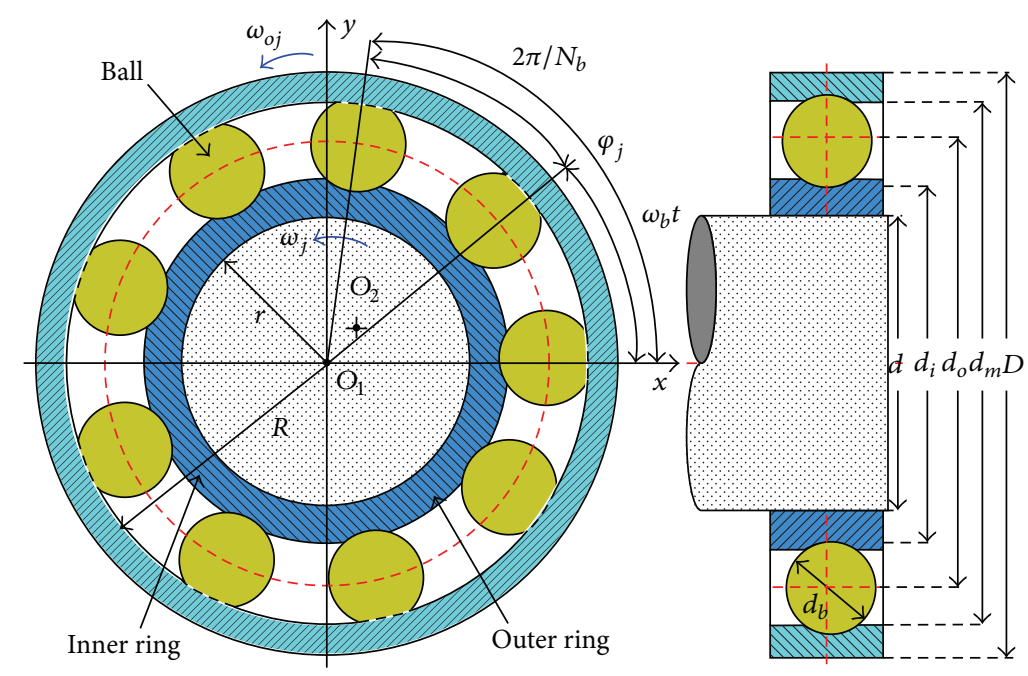

FIGURE 3: Rolling bearing model.

The relationship between $G_{1}$ and $G_{2}$ and $O_{1}$ and $O_{2}$ is expressed as

$$
\begin{aligned}
& x_{g 1}=x_{1}+\rho_{1} \cos \left(-\varphi_{1}\right), \\
& y_{g 1}=y_{1}+\rho_{1} \sin \left(-\varphi_{1}\right), \\
& x_{g 2}=x_{2}+\rho_{2} \cos \varphi_{2}, \\
& y_{g 2}=y_{2}+\rho_{2} \sin \varphi_{2} .
\end{aligned}
$$

In order to ensure the contact of teeth surface on meshing performance, it is assumed that the relative deformation of gear is completely changed into elastic deformation on teeth surface along with the mesh line direction. The meshing gears are connected through the spring and damping. Therefore, the comprehensive deformation between the driving and driven gears along the mesh line direction is expressed as

$$
\begin{aligned}
\delta= & y_{1}-y_{2}+\theta_{1} r_{b 1}-\theta_{2} r_{b 2}+\rho_{1} \sin \left(-\varphi_{1}\right)-\rho_{2} \sin \varphi_{2} \\
& -e(t) .
\end{aligned}
$$

The dynamic meshing force along the line-of-action can be described as

$$
F_{m}=c_{m} \dot{\delta}+k_{m} \delta
$$

where $k_{m}$ and $c_{m}$ represent the average meshing stiffness and damping. $e(t)$ indicates the static transmission error, which can be described as follows:

$$
e(t)=e_{m}+e_{r} \sin \left(\omega_{e} t+\varphi_{e}\right)
$$

here, $e_{m}$ and $e_{r}$ stand for the mean and fluctuation; $\omega_{e}$ is the gear meshing frequency, and $\omega_{e}=2 \pi n_{1} z_{1} / 60=2 \pi n_{2} z_{2} / 60$; $\varphi_{e}$ is the initial phase. $n_{1}$ and $n_{2}$ are rotational speed of gears.

2.2. The Dynamic Model of Rolling Bearing. Figure 3 shows the dynamic model of rolling bearing, bearing outer ring is fixed in bearing chock, and inner ring is fixed in shaft. The balls are uniformly distributed between outer ring and inner ring. $v_{j}$ and $v_{o j}$ are velocities at the contact points between the rolling ball and outer/inner ring, which can be expressed as

$$
\begin{gathered}
v_{j}=\omega_{j} \cdot r, \\
v_{o j}=\omega_{o j} \cdot R,
\end{gathered}
$$

where $R$ and $r$ represent the radius of outer and inner track, respectively, and $\omega_{j}$ and $\omega_{o j}$ are the angular velocity of outer and inner track, respectively.

Assuming that it is pure rolling between ball and outer/inner ring, the velocity of cage can be written as follows:

$$
v_{b}=\frac{\left(v_{o j}+v_{j}\right)}{2}=\frac{\left(\omega_{o j} R+\omega_{j} r\right)}{2} .
$$

Generally, the bearing inner ring rotates together with shaft, and the bearing outer ring is fixed. Utilizing the relationships $\omega_{o j}=0$ and $\omega_{j}=\omega$, the angular velocity of the cage is as follows:

$$
\omega_{b}=\frac{2 v_{b}}{(R+r)}=\frac{\omega \cdot r}{(R+r)} .
$$

The rotational angle $\varphi_{j}$ of the $j$ th rolling ball at $t$ moment can be expressed:

$$
\varphi_{j}=\omega_{b} \cdot t+\frac{2 \pi(j-1)}{N_{b}},
$$

where $N_{b}$ represents the number of rolling balls.

Because the centrifugal force and gyroscopic moment are ignored, the contacting angular between rolling ball and bearing orbit and the contacting force are the same. The deformation of the $j$ th rolling ball can be expressed as

$$
\delta_{j}=x \cos \varphi_{j}+y \sin \varphi_{j}-\gamma_{0}
$$


According to nonlinear Hertz contact theory, the contact force between the $j$ th rolling ball and the bearing orbits is $f_{b j}$; at the same time, the normal stress can be only generated between the rolling ball and the bearing orbits when $\delta_{j}$ is greater than zero. So the force $f_{j}$ can be expressed by [30]

$$
\begin{aligned}
f_{j}= & k_{b}\left(\delta_{j}\right)^{3 / 2} \\
= & k_{b}\left(x \cos \varphi_{j}+y \sin \varphi_{j}-\gamma_{0}\right)^{3 / 2} \\
& \cdot H\left(x \cos \varphi_{j}+y \sin \varphi_{j}-\gamma_{0}\right),
\end{aligned}
$$

where $k_{b}$ is Hertz contact stiffness and $H(x)$ represents Heaviside function and can be written as follows:

$$
H(x) \begin{cases}1 & \text { if } x>0 \\ 0 & \text { if } x \leq 0\end{cases}
$$

So the bearing forces $\left(F_{x}\right.$ and $\left.F_{y}\right)$ in $x$-direction and $y$ direction can be described as follows:

$$
\begin{aligned}
F= & \sum_{j=1}^{N_{b}} f_{j}=\sum_{j=1}^{N_{b}}\left[k_{b}\left(x \cos \varphi_{j}+y \sin \varphi_{j}-\gamma_{0}\right)^{3 / 2}\right. \\
\cdot & \left.H\left(x \cos \varphi_{j}+y \sin \varphi_{j}-\gamma_{0}\right) \cos \varphi_{j}\right], \\
F_{x} & =\sum_{j=1}^{N_{b}} f_{x j}=F \cos \varphi_{j}, \\
F_{y} & =\sum_{j=1}^{N_{b}} f_{y j}=F \sin \varphi_{j} .
\end{aligned}
$$

2.3. Equations of Motion. The model in this paper takes the average meshing stiffness of the spur gears without consideration of meshing backlash and friction. The meshing force $F_{m}$ in direction of contacting line on the tooth surface acts on the center of tooth width. A displacement vector of spur gear system can be defined from the pressure line coordinate system, as shown in Figure 2. The generalized deformation vector can be expressed as follows:

$$
\left[\begin{array}{llllllllllllllll}
\theta_{d} & x_{1} & y_{1} & \theta_{1} & x_{2} & y_{2} & \theta_{2} & x_{b 1} & y_{b 1} & x_{b 2} & y_{b 2} & x_{b 3} & y_{b 3} & x_{b 4} & y_{b 4} & \theta_{l}
\end{array}\right]^{\top},
$$

where $\theta_{d}, \theta_{l}, \theta_{1}$, and $\theta_{2}$ represent the torsional vibration angular displacement of input terminal, output terminal, driving gear, and driven gear, respectively. $x_{i}$ and $y_{i}(i=$ $1,2)$ are the vibration displacement in $x$-direction and $y$ direction of driving and driven gears. $x_{b i}$ and $y_{b i}(i=1-4)$ are the vibration displacement of bearings in $x$-direction and $y$-direction, respectively. Considering the unbalanced force, meshing torque, and input/output torque, the kinetic energy $T$, the potential energy $U$, and the dissipation function $R$ are established of the system. According to Lagrange's equation, the differential equations of the gear system can be expressed by following equations:

$$
\begin{aligned}
& J_{d} \ddot{\theta}_{d}+c_{t 1}\left(\dot{\theta}_{d}-\dot{\theta}_{1}\right)+k_{t 1}\left(\theta_{d}-\theta_{1}\right)=T_{d}, \\
& m_{1} \ddot{x}_{1}+c_{s 1}\left(\dot{x}_{1}-\xi_{2} \dot{x}_{b 1}-\xi_{1} \dot{x}_{b 2}\right) \\
& \quad+k_{s 1}\left(x_{1}-\xi_{2} x_{b 1}-\xi_{1} x_{b 2}\right)=m_{1} \rho_{1} \ddot{\theta}_{1} \sin \left(\omega_{1} t+\theta_{1}\right) \\
& \quad+m_{1} \rho_{1}\left(\omega_{1}+\dot{\theta}_{1}\right)^{2} \cos \left(\omega_{1} t+\theta_{1}\right), \\
& m_{1} \ddot{y}_{1}+c_{s 1}\left(\dot{y}_{1}-\xi_{2} \dot{y}_{b 1}-\xi_{1} \dot{y}_{b 2}\right) \\
& \quad+k_{s 1}\left(y_{1}-\xi_{2} y_{b 1}-\xi_{1} y_{b 2}\right)=m_{1} \rho_{1} \ddot{\theta}_{1} \cos \left(\omega_{1} t+\theta_{1}\right) \\
& \quad-m_{1} \rho_{1}\left(\omega_{1}+\dot{\theta}_{1}\right)^{2} \sin \left(\omega_{1} t+\theta_{1}\right)-F_{m}-m_{1} g, \\
& \left(J_{1}+m_{1} \rho_{1}^{2}\right) \ddot{\theta}_{1}+c_{t 1}\left(\dot{\theta}_{1}-\dot{\theta}_{d}\right)+k_{t 1}\left(\theta_{1}-\theta_{d}\right)
\end{aligned}
$$

$$
\begin{aligned}
& \quad=m_{1} \rho_{1} \sin \left(\omega_{1} t+\theta_{1}\right) \ddot{x}_{1}+m_{1} \rho_{1} \cos \left(\omega_{1} t+\theta_{1}\right) \ddot{y}_{1} \\
& \quad-F_{m} r_{b 1}, \\
& m_{2} \ddot{x}_{2}+c_{s 2}\left(\dot{x}_{2}-\xi_{4} \dot{x}_{b 3}-\xi_{3} \dot{x}_{b 4}\right) \\
& \quad+k_{s 2}\left(x_{2}-\xi_{4} x_{b 3}-\xi_{3} x_{b 4}\right)=m_{2} \rho_{2} \ddot{\theta}_{2} \sin \left(\omega_{2} t+\theta_{2}\right) \\
& \quad+m_{2} \rho_{2}\left(\omega_{2}+\dot{\theta}_{2}\right)^{2} \cos \left(\omega_{2} t+\theta_{2}\right), \\
& m_{2} \ddot{y}_{2}+c_{s 2}\left(\dot{y}_{2}-\xi_{4} \dot{y}_{b 3}-\xi_{3} \dot{y}_{b 4}\right) \\
& \quad+k_{s 2}\left(y_{2}-\xi_{4} y_{b 3}-\xi_{3} y_{b 4}\right) \\
& \quad=-m_{2} \rho_{2} \ddot{\theta}_{2} \cos \left(\omega_{2} t+\theta_{2}\right) \\
& \quad+m_{2} \rho_{2}\left(\omega_{2}+\dot{\theta}_{2}\right)^{2} \sin \left(\omega_{2} t+\theta_{2}\right)+F_{m}-m_{2} g, \\
& \left(J_{2}+m_{2} \rho_{2}^{2}\right) \ddot{\theta}_{2}+c_{t 2}\left(\dot{\theta}_{2}-\dot{\theta}_{l}\right)+k_{t 2}\left(\theta_{2}-\theta_{l}\right) \\
& \quad=m_{2} \rho_{2} \sin \left(\omega_{2} t+\theta_{2}\right) \ddot{x}_{2}-m_{2} \rho_{2} \cos \left(\omega_{2} t+\theta_{2}\right) \ddot{y}_{2} \\
& \quad+F_{m} r_{b 2}, \\
& m_{b 1} \ddot{x}_{b 1}+c_{s 1} \xi_{2}\left(-\dot{x}_{1}+\xi_{2} \dot{x}_{b 1}+\xi_{1} \dot{x}_{b 2}\right)+c_{b x 1} \dot{x}_{b 1} \\
& \quad+k_{s 1} \xi_{2}\left(-x_{1}+\xi_{2} x_{b 1}+\xi_{1} x_{b 2}\right)=F_{x 1}, \\
& m_{b 1} \ddot{y}_{b 1}+c_{s 1} \xi_{2}\left(-\dot{y}_{1}+\xi_{2} \dot{y}_{b 1}+\xi_{1} \dot{y}_{b 2}\right)+c_{b y 1} \dot{y}_{b 1} \\
& \quad+k_{s 1} \xi_{2}\left(-y_{1}+\xi_{2} y_{b 1}+\xi_{1} y_{b 2}\right)=F_{y 1}-m_{b 1} g,
\end{aligned}
$$




$$
\begin{aligned}
& m_{b 2} \ddot{x}_{b 2}+c_{s 1} \xi_{1}\left(-\dot{x}_{1}+\xi_{2} \dot{x}_{b 1}+\xi_{1} \dot{x}_{b 2}\right)+c_{b x 2} \dot{x}_{b 2} \\
& +k_{s 1} \xi_{1}\left(-x_{1}+\xi_{2} x_{b 1}+\xi_{1} x_{b 2}\right)=F_{x 2}, \\
& m_{b 2} \ddot{y}_{b 2}+c_{s 1} \xi_{1}\left(-\dot{y}_{1}+\xi_{2} \dot{y}_{b 1}+\xi_{1} \dot{y}_{b 2}\right)+c_{b y 2} \dot{y}_{b 2} \\
& +k_{s 1} \xi_{1}\left(-y_{1}+\xi_{2} y_{b 1}+\xi_{1} y_{b 2}\right)=F_{y 2}-m_{b 2} g \\
& m_{b 3} \ddot{x}_{b 3}+c_{s 2} \xi_{4}\left(-\dot{x}_{2}+\xi_{4} \dot{x}_{b 3}+\xi_{3} \dot{x}_{b 4}\right)+c_{b x 3} \dot{x}_{b 3} \\
& +k_{s 2} \xi_{4}\left(-x_{2}+\xi_{4} x_{b 3}+\xi_{3} x_{b 4}\right)=F_{x 3}, \\
& m_{b 3} \ddot{y}_{b 3}+c_{s 2} \xi_{4}\left(-\dot{y}_{2}+\xi_{4} \dot{y}_{b 3}+\xi_{3} \dot{y}_{b 4}\right)+c_{b y 3} \dot{y}_{b 3} \\
& +k_{s 2} \xi_{4}\left(-y_{2}+\xi_{4} y_{b 3}+\xi_{3} y_{b 4}\right)=F_{y 3}-m_{b 3} g, \\
& m_{b 4} \ddot{x}_{b 4}+c_{s 2} \xi_{3}\left(-\dot{x}_{2}+\xi_{4} \dot{x}_{b 3}+\xi_{3} \dot{x}_{b 4}\right)+c_{b x 4} \dot{x}_{b 4} \\
& +k_{s 2} \xi_{3}\left(-x_{2}+\xi_{4} x_{b 3}+\xi_{3} x_{b 4}\right)=F_{x 4}, \\
& m_{b 4} \ddot{y}_{b 4}+c_{s 2} \xi_{3}\left(-\dot{y}_{2}+\xi_{4} \dot{y}_{b 3}+\xi_{3} \dot{y}_{b 4}\right)+c_{b y 4} \dot{y}_{b 4} \\
& +k_{s 2} \xi_{3}\left(-y_{2}+\xi_{4} y_{b 3}+\xi_{3} y_{b 4}\right)=F_{y 4}-m_{b 4} g, \\
& J_{l} \ddot{\theta}_{l}+c_{t 2}\left(\dot{\theta}_{l}-\dot{\theta}_{2}\right)+k_{t 2}\left(\theta_{l}-\theta_{2}\right)=-T_{l},
\end{aligned}
$$

where $k_{s i}$ and $c_{s i}(i=1,2)$ are the lateral stiffness and damping of shafts. $k_{t i}$ and $c_{t i}(i=1,2)$ represent the torsional stiffness and damping of shafts. $c_{b x i}$ and $c_{b y i}(i=1-4)$ are the bearing damping in $x$-direction and $y$-direction; $F_{x i}$ and $F_{y i}(i=1-4)$ indicate the bearing force.

\section{The Coupled Lateral-Torsional Vibration of Gear System}

In this paper, the dynamical equations presented in (15) for the spur gear rotor bearing system with the gravity, input/output torque, transmission error, and eccentricity and coupled lateral-torsional vibration are investigated using the Runge-Kutta method. The key parameters are investigated to obtain a basic understanding of the dynamic behaviors of the spur gear system. Table 1 summarizes the geometrical and physical parameters of spur gear system. Let rotational speed, eccentricity, and bearing clearance be control parameters in the following analysis.

Figure 4 is the time domain waveform and the frequency domain response, respectively, at $n_{1}=500 \mathrm{r} / \mathrm{min}$ of the driving and driven spur gears and the corresponding dynamic response of the left bearing in $x$-direction and $y$ -

\begin{tabular}{|c|c|c|}
\hline \multicolumn{3}{|c|}{ Gear parameters } \\
\hline \multirow{2}{*}{ Number of teeth } & $z_{1}$ & 100 \\
\hline & $z_{2}$ & 25 \\
\hline \multirow{2}{*}{ Mass (kg) } & $m_{1}$ & 667.8 \\
\hline & $m_{2}$ & 141.1 \\
\hline \multirow{2}{*}{ Inertia $\left(\mathrm{kg} \cdot \mathrm{m}^{2}\right)$} & $J_{1}$ & 44.4 \\
\hline & $J_{2}$ & 0.207 \\
\hline Modulus & $m$ & 8 \\
\hline \multirow{2}{*}{ Eccentricity } & $\rho_{1}$ & $2.0 \times 10^{-6}$ \\
\hline & $\rho_{2}$ & $2.0 \times 10^{-5}$ \\
\hline Mesh stiffness & $k_{m}$ & $6.0 \times 10^{8}$ \\
\hline Damping ratio & $\xi_{m}$ & 0.1 \\
\hline \multicolumn{3}{|l|}{ Transmission error } \\
\hline Mean & $e_{m}$ & $2 \times 10^{-5}$ \\
\hline Amplitude & $e_{r}$ & $3 \times 10^{-5}$ \\
\hline Angular speed & $\omega_{e}$ & 2000 \\
\hline \multicolumn{3}{|c|}{ Shaft parameters } \\
\hline \multirow{2}{*}{ Bending stiffness } & $k_{s 1}$ & $2.5 \times 10^{8}$ \\
\hline & $k_{s 2}$ & $1.6 \times 10^{7}$ \\
\hline Damping ratio & $\xi_{s}$ & 0.07 \\
\hline \multirow{2}{*}{ Torsional stiffness } & $k_{t 1}$ & $4.3 \times 10^{8}$ \\
\hline & $k_{t 2}$ & $2.5 \times 10^{7}$ \\
\hline Damping ratio & $\xi_{t}$ & 0.07 \\
\hline \multicolumn{3}{|l|}{ Input/output parameters } \\
\hline \multirow{2}{*}{ Rotational inertia } & $J_{d}$ & 17.8 \\
\hline & $J_{l}$ & 5.3 \\
\hline \multirow{2}{*}{ Speed $(\mathrm{r} / \mathrm{min})$} & $\omega_{1}$ & 500 \\
\hline & $\omega_{2}$ & 2000 \\
\hline Gear on the shaft position & $\xi_{1}=\xi_{2}$ & $\xi_{3}=\xi_{4}=0.5$ \\
\hline \multicolumn{3}{|c|}{ Bearing parameters } \\
\hline \multirow{2}{*}{ Lumped mass } & $m_{b 1}, m_{b 2}$ & 115.2 \\
\hline & $m_{b 3}, m_{b 4}$ & 73.2 \\
\hline \multirow{2}{*}{ Bearing stiffness } & $k_{b x 1}, k_{b y 1}$ & $6.0 \times 10^{10}$ \\
\hline & $k_{b x 2}, k_{b y 2}$ & $2.0 \times 10^{10}$ \\
\hline Damping ratio & $\xi_{b}$ & 0.01 \\
\hline \multirow{2}{*}{ Bearing contact stiffness } & $k_{b 1}$ & $13 \times 10^{9}$ \\
\hline & $k_{b 2}$ & $10 \times 10^{9}$ \\
\hline \multirow{2}{*}{ Number of bearing rolling balls } & $N_{b 1}$ & 14 \\
\hline & $N_{b 2}$ & 10 \\
\hline \multirow{2}{*}{ Bearing 1 radius $(\mathrm{m})$} & $R_{1}$ & 0.25 \\
\hline & $r_{1}$ & 0.2 \\
\hline \multirow{2}{*}{ Bearing 2 radius (m) } & $R_{2}$ & 0.125 \\
\hline & $r_{2}$ & 0.1 \\
\hline \multirow{2}{*}{ Bearing clearance (m) } & $\gamma_{01}$ & $2 \times 10^{-7}$ \\
\hline & $\gamma_{02}$ & $5 \times 10^{-7}$ \\
\hline
\end{tabular}
direction (local frequency domain responses are shown in some figures). $x_{1}$ and $y_{1}$ represent vibration displacements of the driving spur gear. $x_{b 1}$ and $y_{b 1}$ are the left bearing vibration displacements of corresponding left bearing. $x_{2}, y_{2}$, $x_{b 2}$, and $y_{b 2}$ indicate the lateral vibration displacements of the corresponding driven gear and bearing. It can be seen from Figure 4(a1-d1) that the driving gear shows significantly different vibration response in lateral direction. The vibration displacement in $y$-direction is larger than that in $x$-direction. In particular, a high-order harmonic component obviously
TABLE 1: Structure and dynamics parameters of spur gear rotor bearing system.

appears in $y$-direction but the harmonic characteristic in $x$ direction is more complicated. From the frequency domain response of the driving gear (Figure 4(a2-b2)) and bearing (Figure $4(\mathrm{c} 2-\mathrm{d} 2)$ ), it can be found that the waveform change 


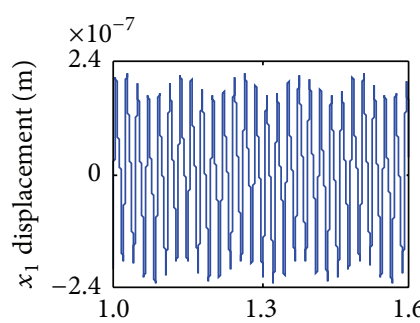

(a1) Time $t$ (s)

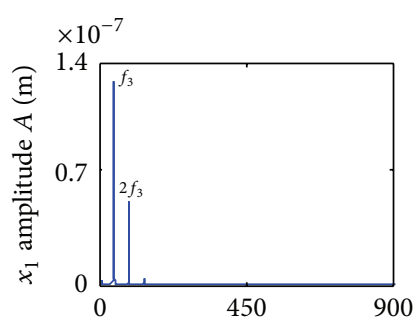

(a2) Frequency $f(\mathrm{~Hz})$

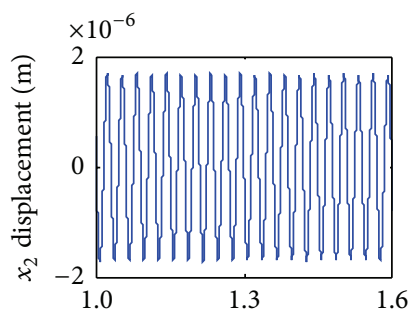

(e1) Time $t$ (s)

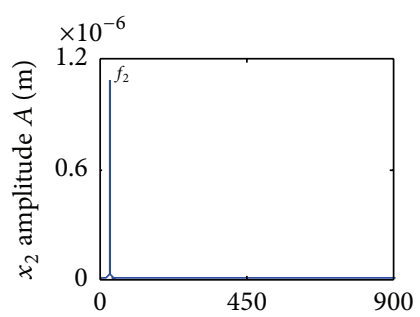

(e2) Frequency $f(\mathrm{~Hz})$

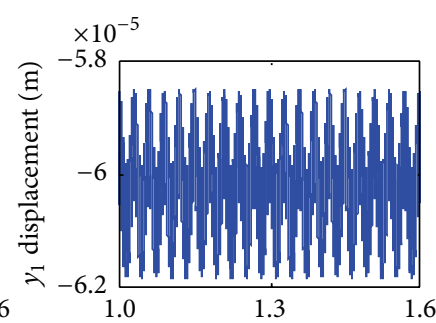

(b1) Time $t$ (s)

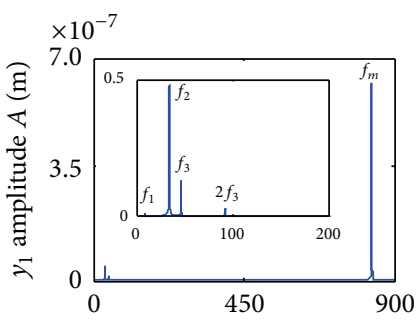

(b2) Frequency $f(\mathrm{~Hz})$

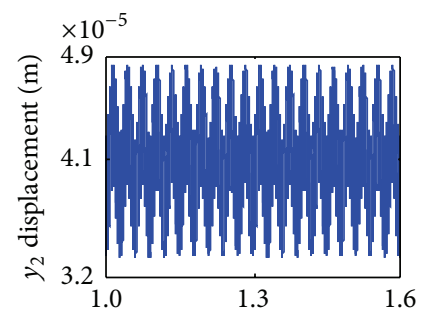

(f1) Time $t$ (s)

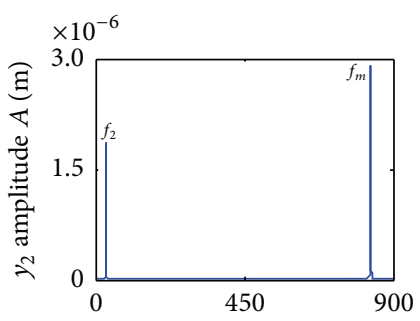

(f2) Frequency $f(\mathrm{~Hz})$

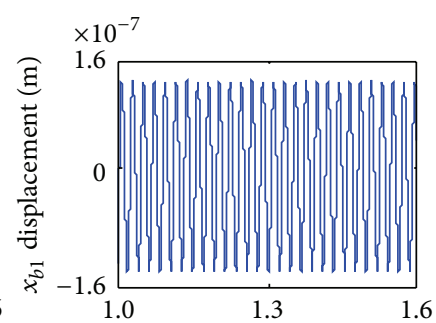

(c1) Time $t$ (s)

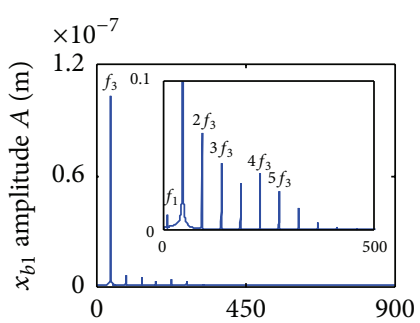

(c2) Frequency $f(\mathrm{~Hz})$

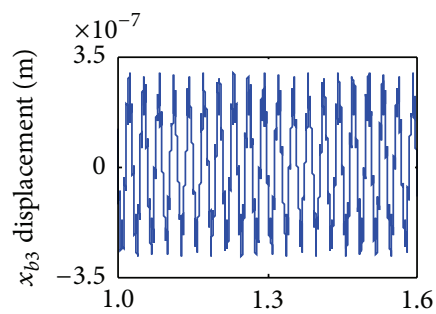

(g1) Time $t$ (s)

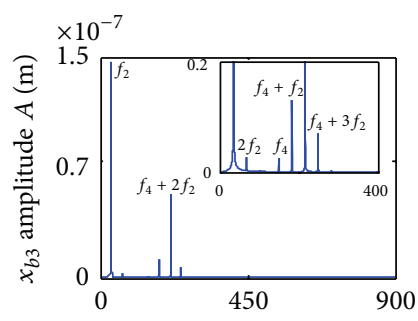

(g2) Frequency $f(\mathrm{~Hz})$

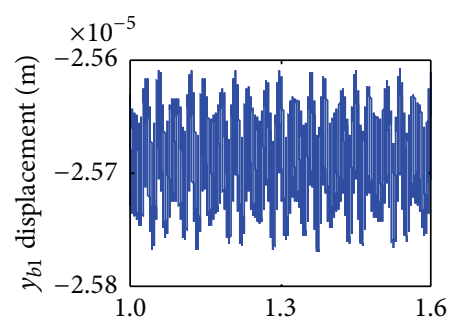

(d1) Time $t$ (s)

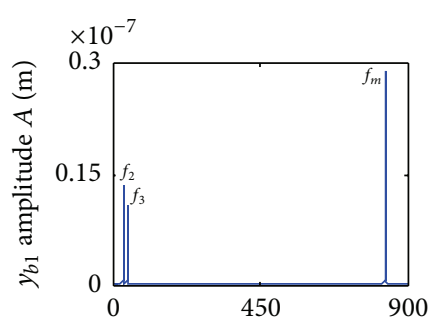

(d2) Frequency $f(\mathrm{~Hz})$

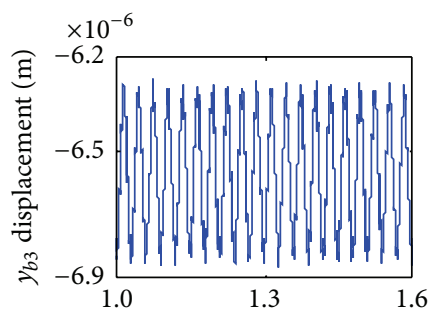

(h1) Time $t$ (s)

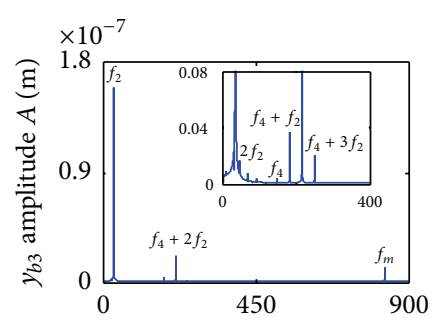

(h2) Frequency $f(\mathrm{~Hz})$

FIgURE 4: Lateral waveform and frequency spectrum at $n_{1}=500 \mathrm{r} / \mathrm{min}, \rho_{1}=2.0 \times 10^{-6} \mathrm{~m}$, and $\rho_{2}=2.0 \times 10^{-5} \mathrm{~m}$.

trend has a little difference. Relative to $x$-direction, a highorder frequency component $f_{m}$ (meshing frequency $n_{1} \times$ $z_{1} / 60=833.3 \mathrm{~Hz}$ ) appears in $y$-direction at gear and bearing position. It also observes that a larger amplitude of the bearing variable stiffness frequency $f_{3}(52 \mathrm{~Hz})$ and frequency multiplication components $\left(2 f_{3}, 3 f_{3} \cdots 6 f_{3}\right)$ appear in $x$ direction of the driving gear in Figure $4(\mathrm{a} 2)$, and $f_{3}$ is the dominated frequency response. However, the frequency components are different from the characteristics in $x$-direction. The meshing frequency $f_{m}$, frequency multiplication $\left(f_{3}\right.$, $\left.2 f_{3}\right)$, and rotational frequencies $f_{1}\left(n_{1} / 60=8.3 \mathrm{~Hz}\right)$ and $f_{2}$ $\left(n_{2} / 60=33.3 \mathrm{~Hz}\right)$ obviously appear. The amplitude of meshing frequency $f_{m}$ is obviously higher than other frequency components. For driving bearing, it shows the obvious bearing variable stiffness frequency $f_{3}$ and multiple frequency components. The amplitudes of other frequency components are relatively lesser in $x$-direction. The frequency components in $y$-direction of the bearing are more complicated. The meshing frequency $f_{m}$ and rotational frequencies $f_{1}$ and $f_{2}$ are also exhibited. Figure 4(e1-h1) shows the lateral vibration responses of the driven gear. From the waveform, it can be seen that the vibration amplitudes in $x$-direction and $y$ direction have an obvious difference, which is caused by two intermeshing gears. In addition, the high-order frequency component $f_{m}$ appears in $y$-direction of driven gear and bearing. In Figure 4(e2-f2), the frequency component of the driven gear is relatively single. The rotational frequency $f_{2}$ clearly appears in $x$-direction and $y$-direction. In addition, the meshing frequency $f_{m}$ only exists in $y$-direction. Meanwhile, the frequency features of the driven gear are more complicated than driving gear, which contains more frequency components such as the rotational frequency $f_{2}$, 
bearing variable stiffness frequency $f_{4}(147.4 \mathrm{~Hz})$, frequency multiplication, and frequency combination components $\left(f_{2}+\right.$ $\left.f_{4}, 2 f_{2}+f_{4}, \ldots\right)$.

Figure 5 shows the torsional vibration of the gears. It can be seen from Figures (a1)-(b1) that the vibration displacement of the driving gear is positive and the vibration displacement of the driven gear is negative. The phenomenon is mainly caused by the coordinates and meshing characteristic. Torsional amplitude of the driven gear is higher because of the different torsional stiffness of shaft. From the frequency domain response, it can be found that the rotational frequencies $f_{1}$ and $f_{2}$ and the meshing frequency $f_{m}$ are shown in Figure 5(a2 b2), in which the meshing frequency component is the dominated response, and the amplitudes are much different between driving gear and driven gear.

Based on the above analysis, it is clear that the coupled lateral and torsional vibration of the gear system presents complex dynamic characteristics due to the influence of the gear assembly characteristics, gear geometry parameters, and the support bearing nonlinearity. The rotational frequencies, meshing frequency, the bearing variable stiffness frequency, and frequencies combination appear, which makes the vibration waveforms become more complicated. Due to the influence of the coupled lateral-torsional vibration, the lateral harmonic frequencies (rotational frequencies and meshing frequency) appear in rotational directions, but the bearing variable stiffness frequency does not appear. In order to analyze and investigate nonlinear characteristics of the systems in detail, it is very necessary for them to be systematically carried out by studying the rotational speed, gear eccentricity, and bearing clearance with the coupled lateral and torsional vibration, which are discussed in the following chapters.

3.1. Analysis of the Effect of the Rotational Speed. Figures 6 and 7 show the time domain waveforms and the frequency domain responses, respectively, at $n_{1}=700 \mathrm{r} / \mathrm{min}$. Comparing Figures 4 and 5 with Figures 6 and 7, the vibration characteristics of gears and bearings have a lot of changes in $x$-direction and $y$-direction with different rotational speed. It can be seen from Figure 6 that the harmonic components have obvious difference of vibration waveforms. Namely, not only do the higher-order harmonic components have some increase, but also the vibration amplitudes have growth to some extent in $x$-direction and $y$-direction. The vibration amplitude in $y$-direction is higher than those in $x$ direction (it is in accordance with the proposed analysis), and the waveform features become more complicated. In the figures of frequency domain response, the frequency combination and frequency multiplication of the gears and bearing obviously appear in $x$-direction and $y$-direction. The amplitude of $f_{2}$ in $y$-direction of the driving gear becomes largely obvious, but $f_{1}$ and the variable stiffness frequency $f_{3}$ become inconspicuous. For the driven gear, the waveform features have no obvious change in $x$-direction, where the rotational frequency $f_{2}$ is the main frequency and the meshing frequency $f_{m}$ decreases obviously. With the increase of rotational speed, the amplitudes have growth to some extent. In addition, the rotational frequencies, the frequency multiplication, and frequency combination components have some significant differences, and the behaviors of the spur gear rotor bearing become more complicated.

The torsional vibration of the driving and driven gears is shown in Figure 7 at $n_{1}=700 \mathrm{r} / \mathrm{min}$. Comparing Figure 5 with Figure 7, the positive and negative torsional vibration responses have no difference with the rotational speed fluctuation, and the vibration amplitudes have little increase. In the frequency domain response, it can be seen that the rotational frequencies $f_{1}$ and $f_{2}$ and the meshing frequency $f_{m}$ appear obviously. In addition, the rotational frequency $f_{2}$ is higher significantly, which is the dominated response in torsional direction of the driving gear.

The above part proposes a detailed analysis of the vibration characteristics with $n_{1}=500 \mathrm{r} / \mathrm{min}$ and $n_{1}=700 \mathrm{r} / \mathrm{min}$. In order to analyze more deeply the spur gear system with changing rotational speed, the $3 \mathrm{D}$ frequency spectrum of the system under different rotational speed condition is shown in Figure 8 (only the dynamic responses of gear are given). With the increasing of the rotational speed, in $x$-direction, the variable stiffness frequency $f_{3}$ reaches a response peak of gears at $n_{1}=900 \mathrm{r} / \mathrm{min}\left(n_{2}=3600 \mathrm{r} / \mathrm{min}\right)$, which illustrates that the bearing has its own variable stiffness frequency. Therefore, the effect of the frequency component of the bearing should be avoided during the system designing work. In addition, other frequency components have no significant change. In $y$-direction, the rotational frequency component $f_{1}$ slightly appears. The rotational frequency $f_{2}$ and meshing frequency $f_{m}$ are the main frequency. However, the changing trends for different frequency component are in an opposite way. The meshing frequency $f_{m}$ in $y$ direction decreases gradually; the rotational frequency $f_{2}$ increases with changing rotational speed of the driving gear. In addition, the rotational frequency $f_{2}$ of the driven gear increases firstly and then decreases. Figure $8(\mathrm{cl}-\mathrm{c} 2)$ shows $3 \mathrm{D}$ frequency spectrum of the gears in torsional direction. It can be seen that the rotational frequencies $f_{1}$ and $f_{2}$ and meshing frequency $f_{m}$ appear obviously. $f_{1}$ has no change evidently, and $f_{2}$ increases firstly and then decreases, but the peaks appear in a different position. The meshing frequency $f_{m}$ of driving gear in torsional direction strongly decreases and increases in torsional direction of the driven gear. Comparing the $3 \mathrm{D}$ frequency spectrum in lateral direction and torsional direction, it can be seen that the variable stiffness frequency components are the main characteristics of driving and driven gears in $x$-direction. The rotational frequency $f_{2}$ and meshing frequency $f_{m}$ are the dominated response, and other frequency components obviously appear, which is the same result as that in the previous analysis. In addition, the amplitudes in torsional direction are larger than those in lateral direction. Therefore, the torsional vibration is the dominated response.

3.2. Analysis of the Effect of the Eccentricity. In this section, the eccentricity of driving and driven gears enlarges from $\rho_{1}=2.0 \times 10^{-6} \mathrm{~m}$ and $\rho_{2}=2.0 \times 10^{-5} \mathrm{~m}$ to $\rho_{1}=$ $4.0 \times 10^{-6} \mathrm{~m}$ and $\rho_{2}=4.0 \times 10^{-5} \mathrm{~m}$. Figures 9 and 10 show the vibration responses of the spur gear rotor bearing system. Comparing Figure 4 with Figure 9, the vibration 


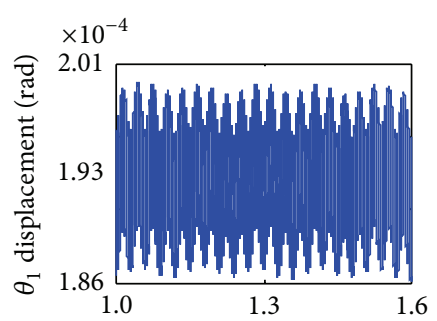

(a1) Time $t$ (s)

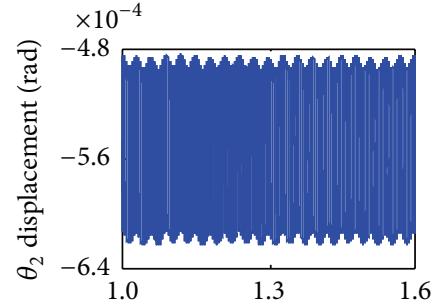

(b1) Time $t$ (s)

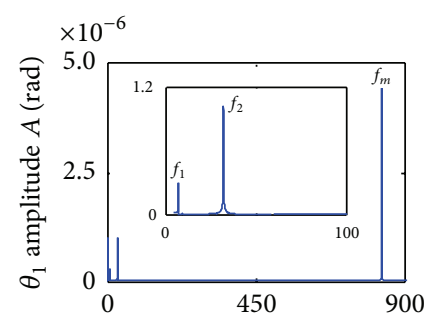

(a2) Frequency $f(\mathrm{~Hz})$

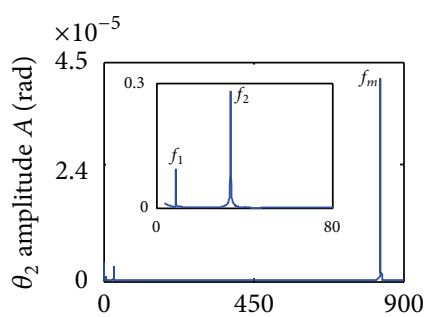

(b2) Frequency $f(\mathrm{~Hz})$

Figure 5: Torsional waveform and frequency spectrum at $n_{1}=500 \mathrm{r} / \mathrm{min}, \rho_{1}=2.0 \times 10^{-6} \mathrm{~m}$, and $\rho_{2}=2.0 \times 10^{-5} \mathrm{~m}$.

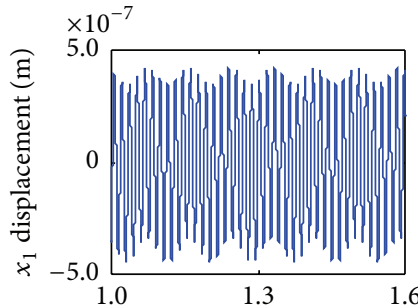

(a1) Time $t$ (s)

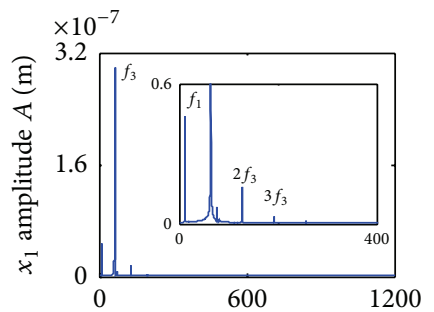

(a2) Frequency $f(\mathrm{~Hz})$

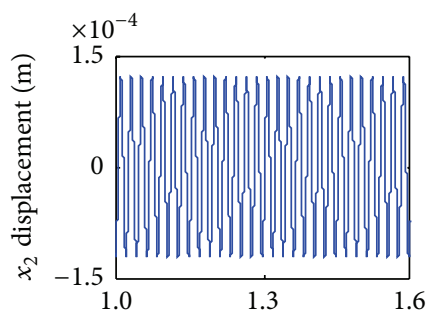

(e1) Time $t(\mathrm{~s})$

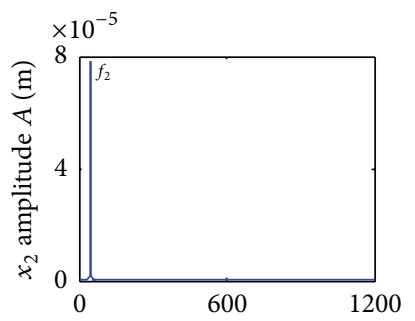

(e2) Frequency $f(\mathrm{~Hz})$

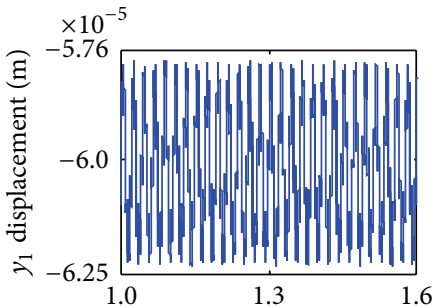

(b1) Time $t$ (s)

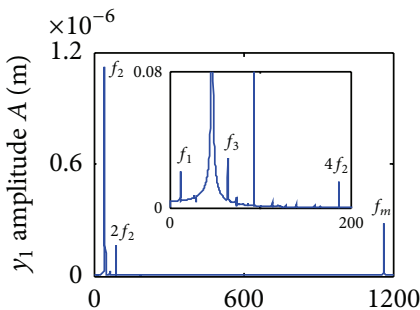

(b2) Frequency $f(\mathrm{~Hz})$

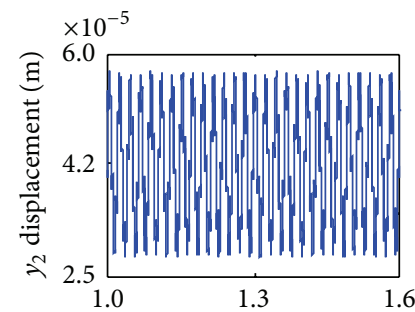

(f1) Time $t(\mathrm{~s})$

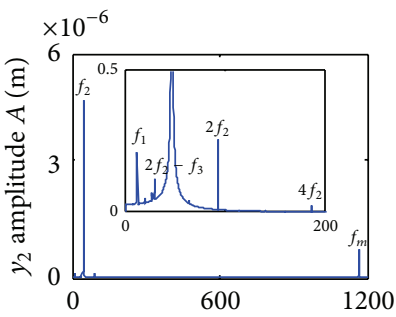

(f2) Frequency $f(\mathrm{~Hz})$

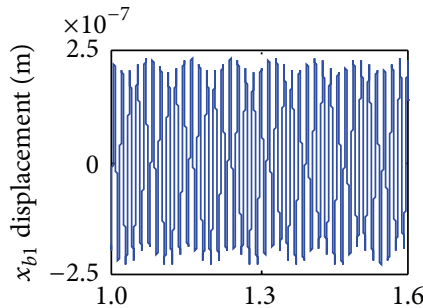

(c1) Time $t$ (s)

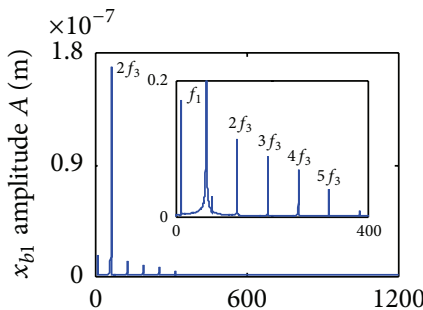

(c2) Frequency $f(\mathrm{~Hz})$

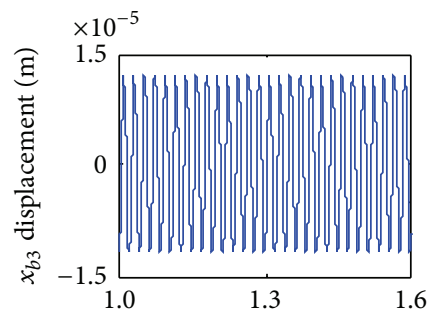

(g1) Time $t(\mathrm{~s})$

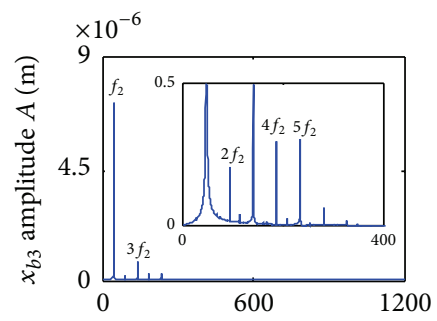

(g2) Frequency $f(\mathrm{~Hz})$

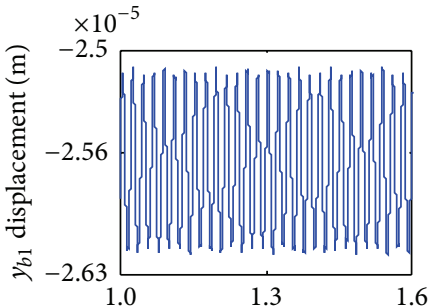

(d1) Time $t$ (s)

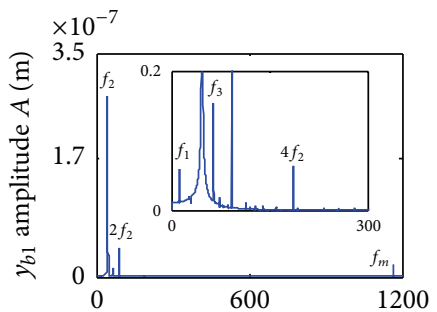

(d2) Frequency $f(\mathrm{~Hz})$

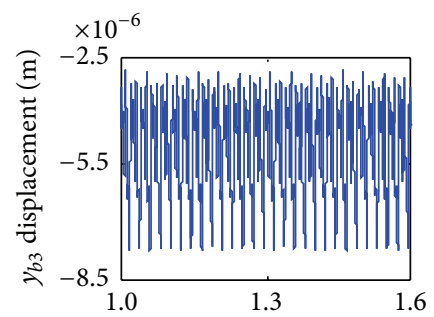

(h1) Time $t$ (s)

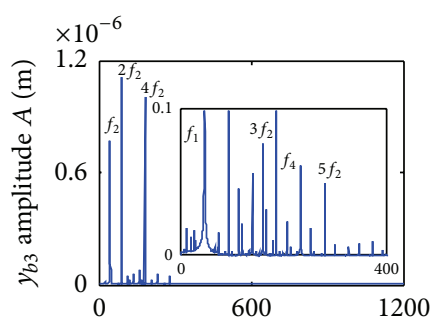

(h2) Frequency $f(\mathrm{~Hz})$

FIGURE 6: Lateral waveform and frequency spectrum at $n_{1}=700 \mathrm{r} / \mathrm{min}, \rho_{1}=2.0 \times 10^{-6} \mathrm{~m}$, and $\rho_{2}=2.0 \times 10^{-5} \mathrm{~m}$.

characteristics and frequency components of gears and bearings have obvious differences in $x$-direction and $y$-direction with increasing gears' eccentricity; in particular the vibration amplitude of gear and bearing significantly increases, but the fluctuation trend is almost invariant. For the driving gear, the vibration amplitude in $y$-direction is obviously higher than that in $x$-direction. It also can be found from the $3 \mathrm{D}$ frequency spectrum that the variable stiffness frequency 


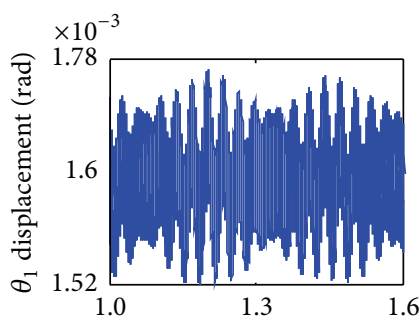

(a1) Time $t(\mathrm{~s})$

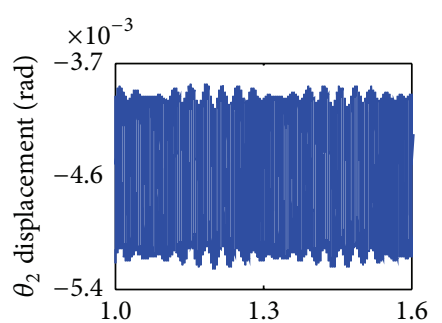

(b1) Time $t(\mathrm{~s})$

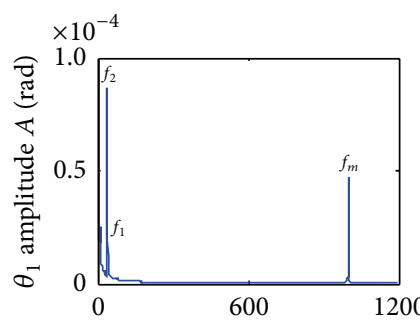

(a2) Frequency $f(\mathrm{~Hz})$

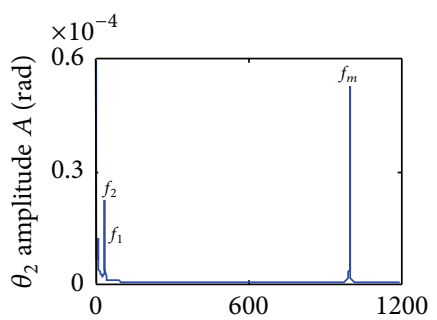

(b2) Frequency $f(\mathrm{~Hz})$

FIGURE 7: Torsional waveform and frequency spectrum at $n_{1}=700 \mathrm{r} / \mathrm{min}, \rho_{1}=2.0 \times 10^{-6} \mathrm{~m}$, and $\rho_{2}=2.0 \times 10^{-5} \mathrm{~m}$.

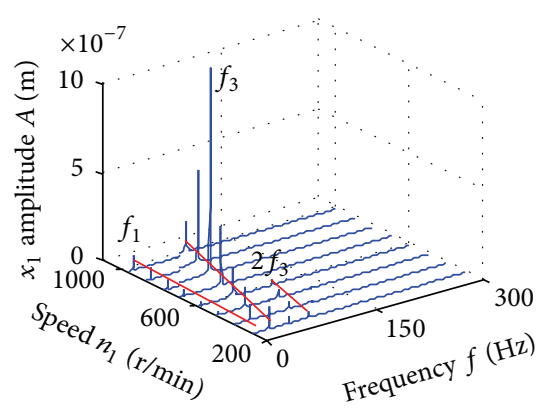

(a1)

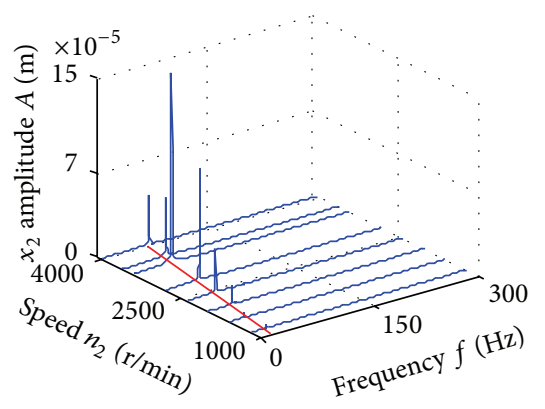

(a2)

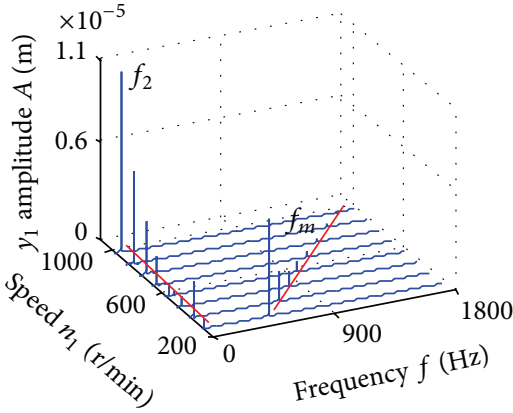

(b1)

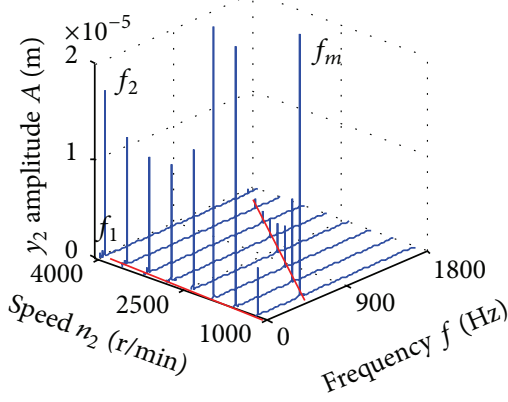

(b2)

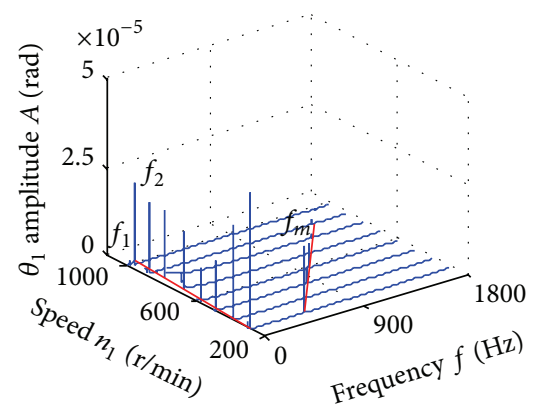

$(\mathrm{c} 1)$

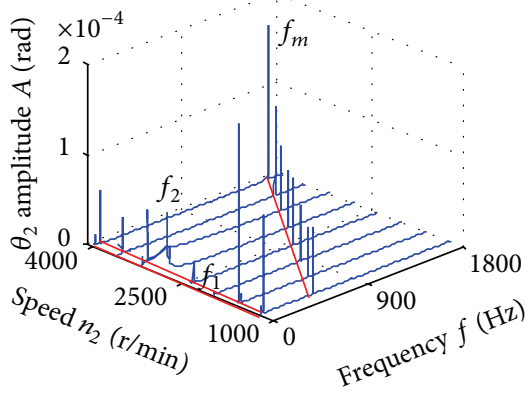

(c2)

FIGURE 8: 3D frequency spectrum of the gears in lateral and torsional directions.

$f_{3}$ is still the main frequency in $x$-direction. In addition, the rotational frequency $f_{1}$ and frequency multiplication $3 f_{3}$ appear significantly, but the frequency amplitudes have almost no change. The frequency amplitudes are higher in $y$-direction and the frequency components become more complicated (some components need to enlarge). Besides, the amplitude of $f_{2}$ is the dominated component with the increasing eccentricity. For the driving bearing, $f_{3}$ and $f_{1}$ and frequency multiplication $\left(2 f_{3}, 3 f_{3}, \ldots\right)$ also obviously appear, and the frequency amplitudes have no obvious increase with the increasing of eccentricity. Comparing Figure 9(e1h1) with Figure 4(e1-h1), it can be found that the vibration amplitudes become higher in $x$-direction and $y$-direction when eccentricity increases; the harmonic components of waveform have no obvious change. The comparison proves that the frequency multiplication components become more obvious and the vibration amplitudes are higher. In $y$ direction, $f_{2}$ becomes the dominated response. For the driven bearing, the frequency combination components disappear gradually, and the frequency multiplication components $\left(2 f_{2}, 3 f_{2}, \ldots\right)$ are more prominent. The rotational frequency $f_{2}$ is still the main frequency component. According to the previous analysis, it can be found that the vibration characteristics of the driving gear/bearing are similar to the driven gear/bearing ones, which may be associated with the flexibility of shafts.

Comparing Figure 5 with Figure 10, it can be found that the torsional vibration amplitudes of gears increase obviously, and the waveforms have obvious fluctuation. Besides, the frequency components have no obvious change. However, the amplitudes of the rotational frequencies and the meshing frequency components increase gradually, which are almost one time higher. The frequency components of driven gear are relatively high in the frequency spectrum, which is related to the flexibility of driven shaft and $f_{m}$ is also the main frequency component. Therefore, it can be seen that the 


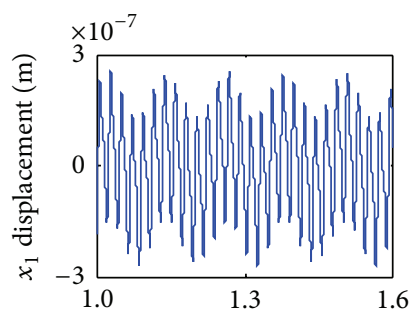

(a1) Time $t$ (s)

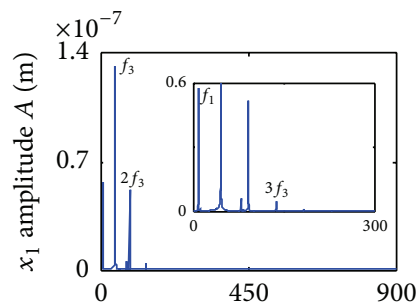

(a2) Frequency $f(\mathrm{~Hz})$

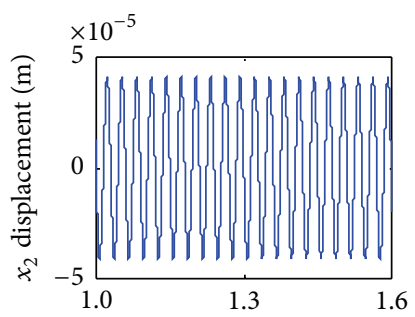

(e1) Time $t$ (s)

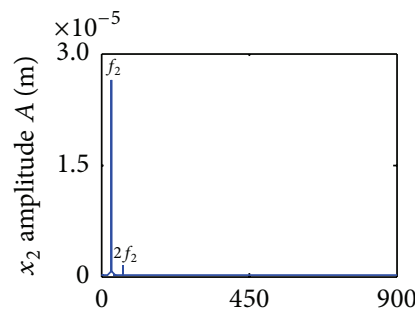

(e2) Frequency $f(\mathrm{~Hz})$

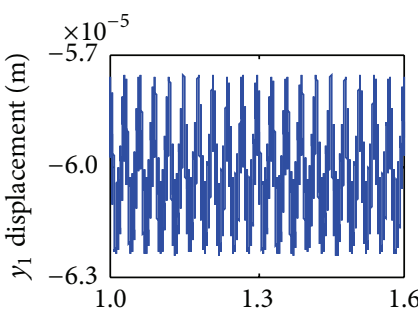

(b1) Time $t$ (s)

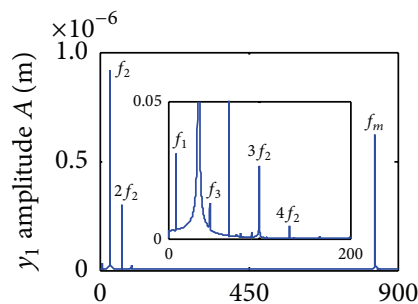

(b2) Frequency $f(\mathrm{~Hz})$

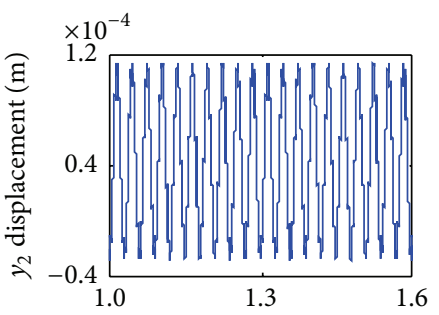

(f1) Time $t(\mathrm{~s})$

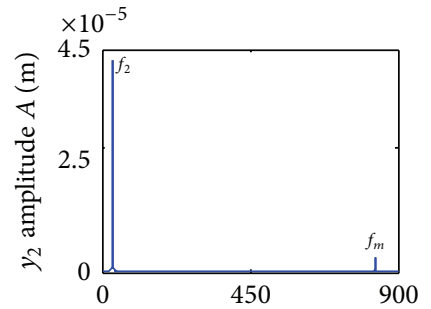

(f2) Frequency $f(\mathrm{~Hz})$

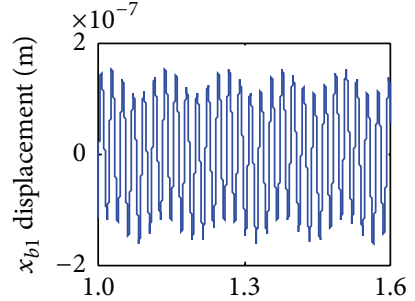

(c1) Time $t$ (s)

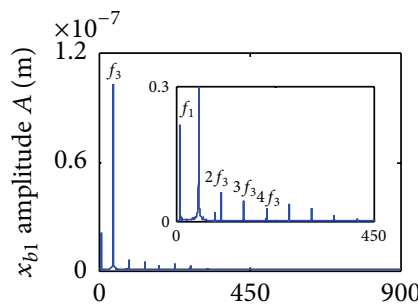

(c2) Frequency $f(\mathrm{~Hz})$

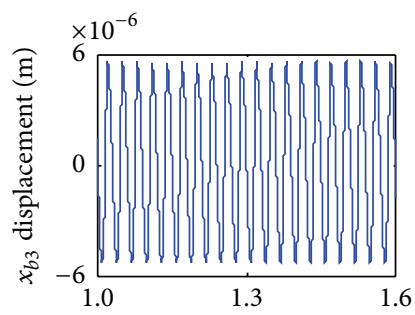

(g1) Time $t$ (s)

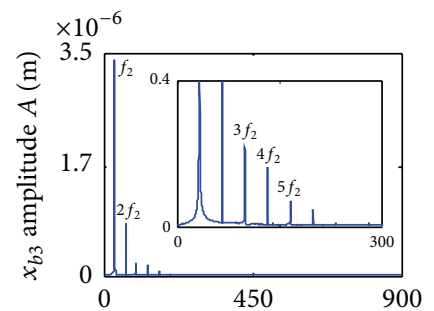

(g2) Frequency $f(\mathrm{~Hz})$

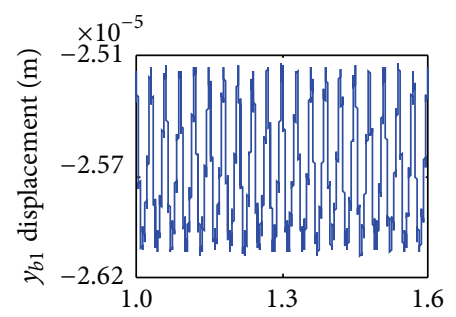

(d1) Time $t$ (s)

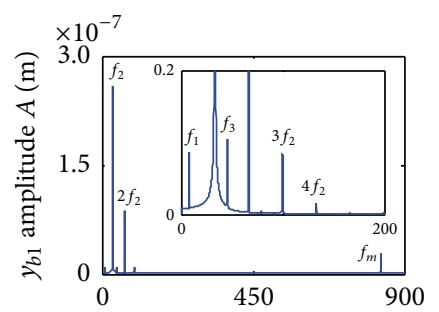

(d2) Frequency $f(\mathrm{~Hz})$

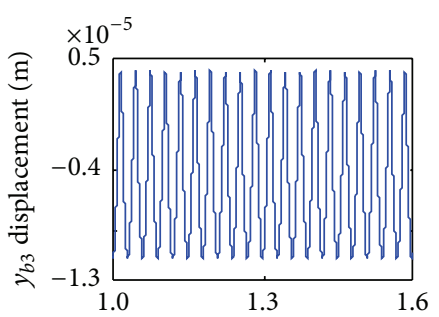

(h1) Time $t$ (s)

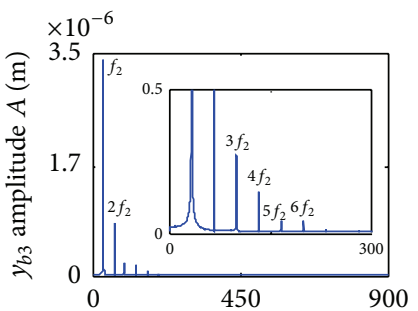

(h2) Frequency $f(\mathrm{~Hz})$

FIGURE 9: Waveform and spectrum diagram at $n_{1}=500 \mathrm{r} / \mathrm{min}, \rho_{1}=4.0 \times 10^{-6} \mathrm{~m}$, and $\rho_{2}=4.0 \times 10^{-5} \mathrm{~m}$.

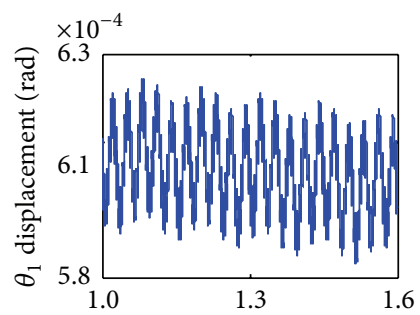

(a1) Time $t$ (s)

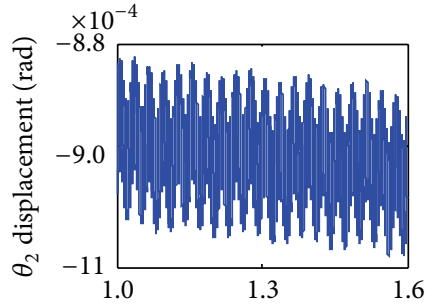

(b1) Time $t$ (s)

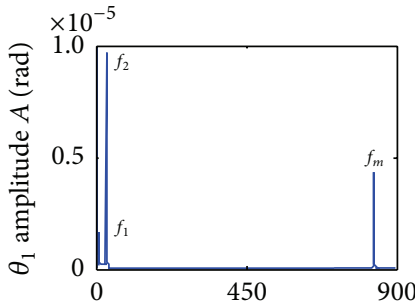

(a2) Frequency $f(\mathrm{~Hz})$

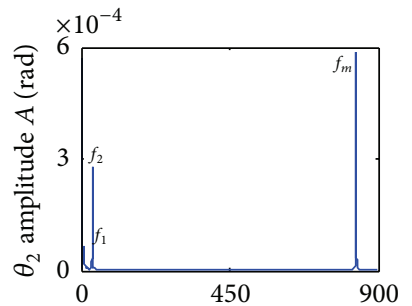

(b2) Frequency $f(\mathrm{~Hz})$

FIGURE 10: Torsional waveform and spectrum diagram at $n_{1}=500 \mathrm{r} / \mathrm{min}, \rho_{1}=4.0 \times 10^{-6} \mathrm{~m}$, and $\rho_{2}=4.0 \times 10^{-5} \mathrm{~m}$.

eccentricity has obvious effect on the amplitudes of the gear in rotational direction. The detailed analysis will be shown in the following section.

In above analysis, the response characteristics with $\rho_{1}=$ $2.0 \times 10^{-6} \mathrm{~m}$ and $\rho_{2}=2.0 \times 10^{-5} \mathrm{~m}$ and $\rho_{1}=4.0 \times 10^{-6} \mathrm{~m}$ and $\rho_{2}=4.0 \times 10^{-5} \mathrm{~m}$ are studied in detail. In order to investigate the effect of the eccentricity, the 3D frequency spectrum of the system is shown in Figure 11. It can be seen from Figure 11 that the frequency components of driving and driven gears exist obvious difference, which is caused by the changing of 


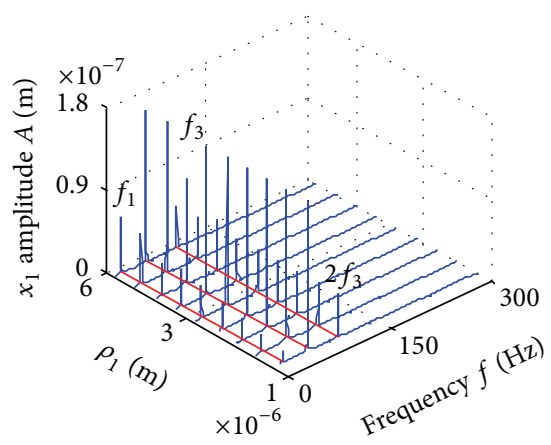

(a1)

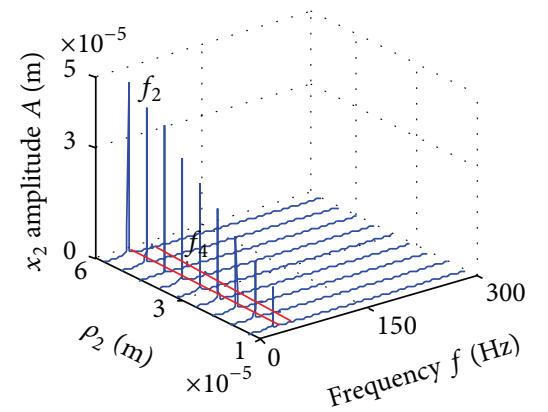

(a2)

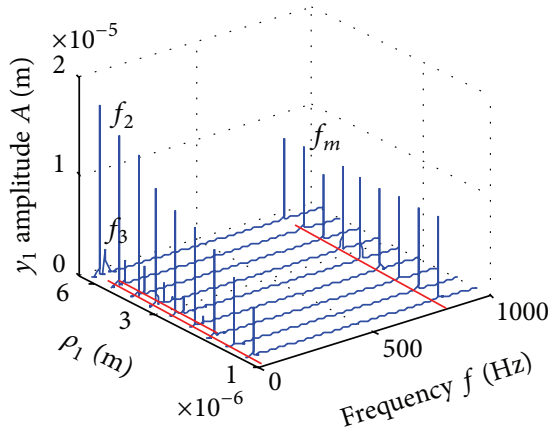

(b1)

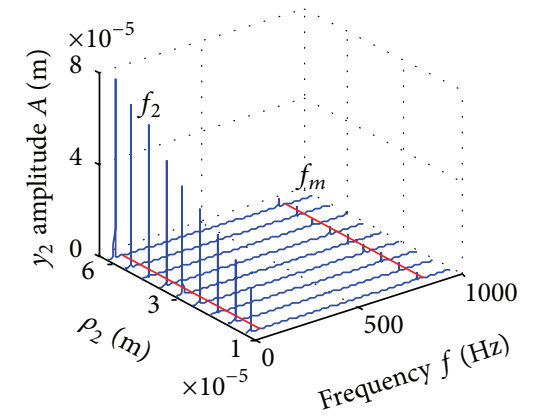

(b2)

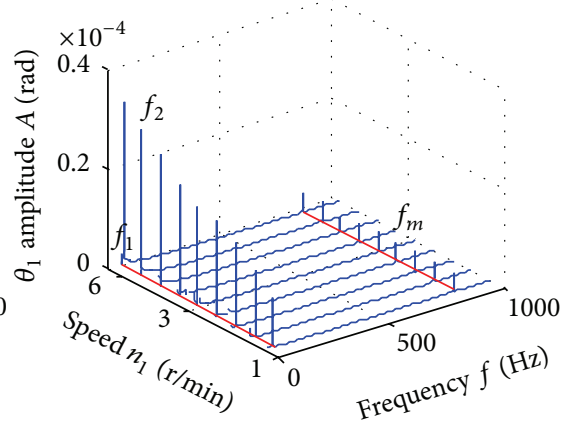

(c1)

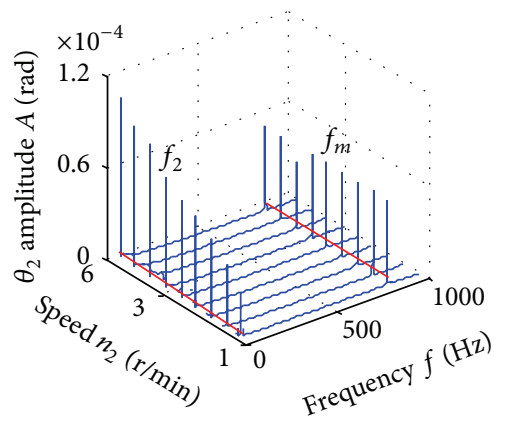

(c2)

FIGURE 11: 3D frequency spectrum of the gears in lateral and torsional directions.

eccentricity. For the driving gear, the rotational frequency $f_{1}$ increases gradually, the variable stiffness frequency $f_{3}$ appears as the minimum value when the eccentricity reaches $\rho_{1}=5.0 \times 10^{-6} \mathrm{~m}$, but the frequency multiplication $\left(2 f_{3}\right)$ increases firstly and then decreases slightly in $x$-direction. The amplitude of $f_{2}$ and variable stiffness frequency amplitude $f_{3}$ increase gradually with the increasing of eccentricity in $y$-direction, and the meshing frequency component $f_{m}$ presents a state of fluctuating increase. However, due to coupled lateral-torsional vibration, $f_{2}$ appears in $y$-direction. For the driven gear, $f_{2}$ becomes the main frequency in $x$ direction, which is due to the high rotational speed of driven gear, and the amplitude of $f_{2}$ presents a state of fluctuating increase with the changing of the eccentricity. In addition, the variable stiffness frequency $f_{4}$ exhibits, but the amplitude has no obvious change. The meshing frequency component $f_{m}$ only appears in $y$-direction, and the amplitude increases slightly. Moreover, the frequency multiplication and random frequency components do not appear. In torsional direction, the amplitudes are similar to the driving and driven gears with the change of eccentricity. $f_{1}, f_{2}$, and $f_{m}$ components are the dominated responses in rational direction. In addition, the frequency amplitudes increase gradually and the frequency amplitude of driven gear is higher than those of driving gear. Based on that previous analysis, with the changing of eccentricity, the frequency components in all positions are increasing, but they are not monotonic increase, and the change tendency of frequency is basically identical.

3.3. Analysis of the Effect of the Bearing Clearance. This section will analyze the influence of the bearing clearance.
The vibration characteristics caused by changing bearing clearance are similar to the foregoing ones. Because of the limited space, this paper does not discuss the time domain response, and Figure 12 presents the $3 \mathrm{D}$ frequency spectrum of the key positions. For the driving gear, it can be found that the frequency $f_{3}$ is the dominated response, and the amplitude shows obvious jump discontinuity with the changing of the bearing clearance in $x$-direction. The amplitudes of $f_{1}$ and the frequency multiplication $\left(2 f_{3}\right)$ are relatively lesser, and the change trends are not obvious. Moreover, the rotational frequency $f_{2}$ and the meshing frequency $f_{m}$ are obvious in $y$-direction and $f_{m}$ is the dominated response. The bearing variable stiffness frequency $f_{3}$ also appears, but $f_{1}$ is not obvious. In addition, the amplitude $f_{2}$ decreases with fluctuation and random frequency components mainly concentrated on $f_{2}$ nearby. For the driven gear, because of the high rotational speed, the rotational frequency $f_{2}$ appears obviously. The frequency component is relatively simple in $x$ direction, in which the rotational frequency $f_{2}$ is the main frequency, the bearing variable stiffness frequency $f_{3}$ appears slightly, and others are not obvious. The amplitude of $f_{2}$ increases gradually. With the increasing of bearing clearance, the frequency amplitude $f_{2}$ in $y$-direction decreases firstly and then increases, but the phenomenon is not obvious. In addition, the meshing frequency $f_{m}$ component has no significant change. The $3 \mathrm{D}$ frequency spectrum in torsional direction of the gears is shown in Figure 12(c1-c2). It can be seen that $f_{1}$ and $f_{m}$ components are the main frequency response. The amplitude of $f_{1}$ decreases gradually with the changing of bearing clearance. Moreover, the rotational frequency $f_{1}$ and meshing frequency $f_{m}$ are dominated 


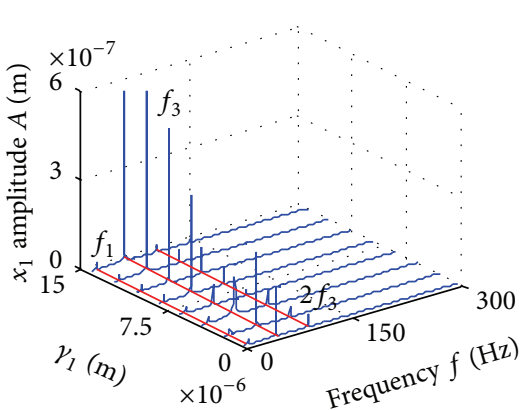

(a1)

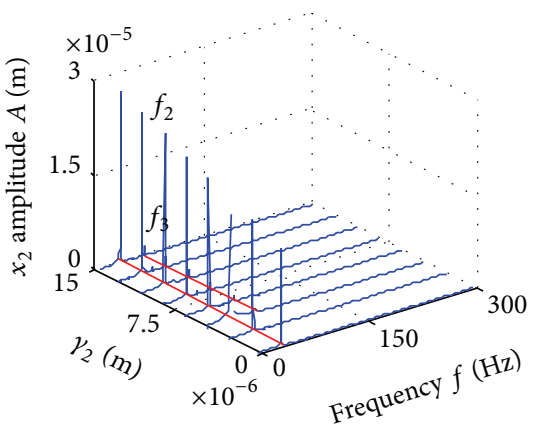

(a2)

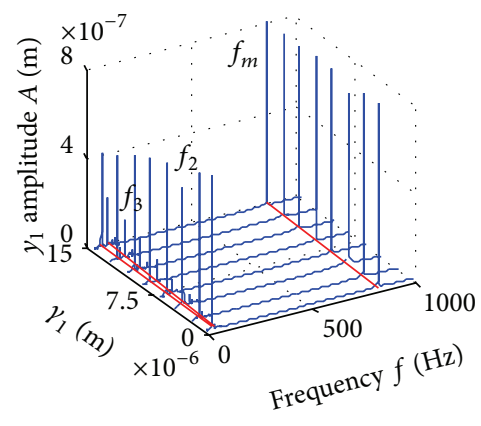

(b1)

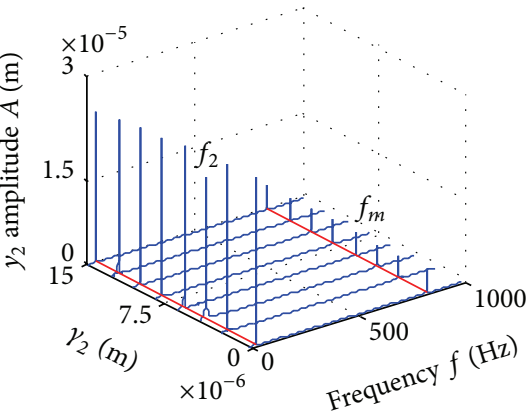

(b2)

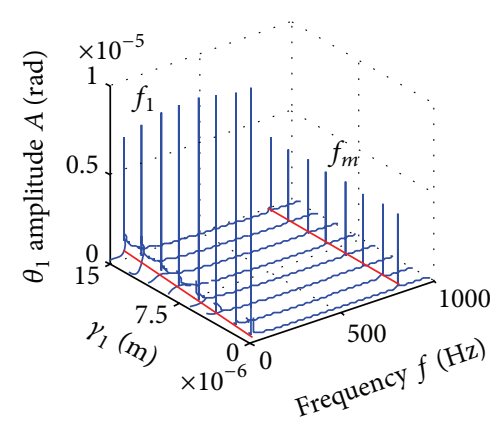

(c1)

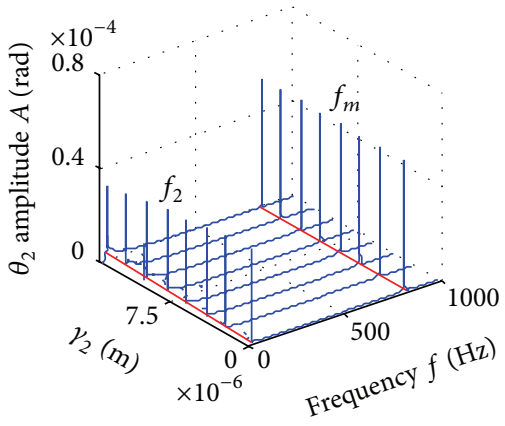

(c2)

FIGURE 12: 3D frequency spectrum of the gears in lateral and torsional directions.

response in driven gear; the frequency amplitudes have almost no changes. Based on the results studied in the previous sections, it can be seen that the bearing clearance has a significant effect on the dynamic characteristics. Therefore, the vibration features of bearing clearance are sensitive and more attention needs to be paid to the designing work.

\section{Conclusion}

A 16-DOF lumped parameter dynamic model taking into account the gravity, eccentricity, bearing clearance, transmission error, and coupled lateral-torsional vibration is established. The effects of rotational speed, eccentricity, and bearing clearance are investigated. Based on the results of the parametric study presented in the previous section, the conclusions can be summarized as follows:

(1) Because of the intermeshing of gears, there is a coupled relationship between the lateral vibration and the torsional vibration of the spur gear rotor bearing system. Hence, for the system, it is very necessary to take into account the coupled lateral-torsional vibration.

(2) Due to the effects of coupled lateral-torsional vibration, the rotational frequency $f_{2}$ and variable stiffness frequency $f_{3}$ components obviously exist in the driving gear. The rotational frequencies $f_{1}$ and $f_{2}$ and the meshing frequency $f_{m}$ components are very obvious in the torsional vibration, which have different characteristics with the changing of the rotational speed.
The bearing has its own resonance frequency, and the effect of the variable stiffness frequency of the bearing in system should be avoided during the system design stage.

(3) With the increasing of the eccentricity, the vibration amplitudes of gears increase gradually and the frequency multiplication and random frequency components become obvious. Therefore, it is necessary to avoid the gear eccentricity. In addition, the processing gear eccentricity and installation error should be given full attention. The bearing clearance has a greater effect on the dynamic characteristics of the system. Selecting the appropriate bearing clearance can reduce the vibration amplitude. Therefore, the bearing clearance needs to pay more attention to the designing work.

\section{Conflict of Interests}

The authors declare that there is no conflict of interests regarding the publication of this paper.

\section{Acknowledgment}

The authors gratefully acknowledge the financial support provided by Natural Science Foundation of China (no. 51475084). 


\section{References}

[1] H. H. Lin, R. L. Huston, and J. J. Coy, "On dynamic loading in parallel shaft transmissions," Journal of Mechanism, Transmissions, and Automation in Design, vol. 110, no. 2, pp. 221-229, 1987.

[2] H. H. Lin, "Dynamic loading of super gear with linear or parabolic tooth profile modification," Journal of Mechanism, Transmissions, and Automation in Design, vol. 29, no. 8, pp. 11151129, 1994.

[3] A. Raghothama and S. Narayanan, "Bifurcation and chaos in geared rotor bearing system by incremental harmonic balance method," Journal of Sound and Vibration, vol. 226, no. 3, pp. 469-492, 1999.

[4] J. W. Lund, "Critical speeds, stability and response of a geared train of rotors," Journal of Mechanical Design, vol. 100, no. 3, pp. 535-538, 1978.

[5] H. Iida, A. Tamura, K. Kikuch, and H. Agata, "Coupled torsional-flexural vibration of a shaft in a geared system of rotors," Bulletin of the JSME, vol. 23, no. 186, pp. 2111-2117, 1980.

[6] A. Kahraman and R. Singh, "Non-linear dynamics of a spur gear pair," Journal of Sound and Vibration, vol. 142, no. 1, pp. 49-75, 1990.

[7] A. Kahraman and R. Singh, "Nonlinear dynamic of geared rotor-bearing system with multiple clearances," Journal of Sound and Vibration, vol. 144, no. 3, pp. 469-506, 1991.

[8] A. Kahraman and R. Singh, "Interactions between time-varying mesh stiffness and clearance non-linearities in a geared system," Journal of Sound and Vibration, vol. 146, no. 1, pp. 135-156, 1991.

[9] G. W. Blankenship and A. Kahraman, "Steady state forced response of a mechanical oscillator with combined parametric excitation and clearance type non-linearity," Journal of Sound and Vibration, vol. 185, no. 5, pp. 743-765, 1995.

[10] Y. H. Sun, C. Zhang, F. Z. Pan, S. Chen, and F. Huang, "Dynamic model of a spur gear transmission system vibration," Chinese Journal of Mechanical Engineering, vol. 36, no. 8, pp. 47-54, 2000 (Chinese).

[11] W. Dou, N. Zhang, and Z.-S. Liu, "The coupled bending and torsional vibrations of the high-speed geared rotor-bearing system," Journal of Vibration Engineering, vol. 24, no. 4, pp. 385393, 2011 (Chinese).

[12] A. S. Lee, J. W. Ha, and D.-H. Choi, "Coupled lateral and torsional vibration characteristics of a speed increasing geared rotor-bearing system," Journal of Sound and Vibration, vol. 263, no. 4, pp. 725-742, 2003.

[13] J. H. Kuang and A. D. Lin, "The effect of tooth wear on the vibration spectrum of a spur gear pair," Journal of Vibration and Acoustics, Transactions of the ASME, vol. 123, no. 3, pp. 311-317, 2001.

[14] W. Y. Kim, H. H. Yoo, and J. T. Chung, "Dynamic analysis for a pair of spur gears with translational motion due to bearing deformation," Journal of Sound and Vibration, vol. 329, no. 21, pp. 4409-4421, 2010.

[15] P. Velex and M. Ajmi, "Dynamic tooth loads and quasistatic transmission errors in helical gears-approximate dynamic factor formulae," Mechanism and Machine Theory, vol. 42, no. 11, pp. 1512-1526, 2007.

[16] C.-J. Bahk and R. G. Parker, "Analytical solution for the nonlinear dynamics of planetary gears," Journal of Computational and Nonlinear Dynamics, vol. 6, no. 2, Article ID 021007, pp. 1-15, 2011.
[17] M. Faggioni, F. S. Samani, G. Bertacchi, and F. Pellicano, "Dynamic optimization of spur gears," Mechanism and Machine Theory, vol. 46, no. 4, pp. 544-557, 2011.

[18] F. L. Litvin, D. Vecchiato, K. Yukishima, A. Fuentes, I. GonzalezPerez, and K. Hayasaka, "Reduction of noise of loaded and unloaded misaligned gear drives," Computer Methods in Applied Mechanics and Engineering, vol. 195, no. 41-43, pp. 5523-5536, 2006.

[19] F. K. Omar, K. A. F. Moustafa, and S. Emam, "Mathematical modeling of gearbox including defects with experimental verification," Journal of Vibration and Control, vol. 18, no. 9, pp. 13101321, 2012.

[20] H. Ma, J. Yang, R. Z. Song, S. Zhang, and B. Wen, "Effects of tip relief on vibration responses of a geared rotor system," Journal of Mechanical Engineering Science, vol. 228, no. 7, pp. 1132-1154, 2014.

[21] H. Ma, Q. B. Wang, and J. Huang, "Vibration response analysis of gear coupled rotor system considering geometric eccentric effect of helical gears," Journal of Aerospace Power, vol. 28, no. 1, pp. 16-24, 2013 (Chinese).

[22] C.-W. Chang-Jian and C.-K. Chen, "Nonlinear dynamic analysis of a flexible rotor supported by micropolar fluid film journal bearings," International Journal of Engineering Science, vol. 44, no. 15-16, pp. 1050-1070, 2006.

[23] S. P. Yang, Y. J. Shen, and X. D. Liu, "Nonlinear dynamics of gear system based on incremental harmonic balance method," Zhendong yu Chongji/Journal of Vibration and Shock, vol. 24, no. 3, pp. 40-95, 2005 (Chinese).

[24] Y. J. Shen, S. P. Yang, and X. D. Liu, "Nonlinear dynamics of a spur gear pair with time-varying stiffness and backlash based on incremental harmonic balance method," International Journal of Mechanical Sciences, vol. 48, no. 11, pp. 1256-1263, 2006.

[25] J. Y. Yang, T. Peng, and T. C. Lim, "An enhanced multi-term harmonic balance solution for nonlinear period-one dynamic motions in right-angle gear pairs," Nonlinear Dynamics, vol. 67, no. 2, pp. 1053-1065, 2012.

[26] S. Wu, M. J. Zuo, and A. Parey, "Simulation of spur gear dynamic and estimation of fault growth," Journal of Sound and Vibration, vol. 317 , no. $3-5$, pp. 608-624, 2008.

[27] L. Walha, T. Fakhfakh, and M. Haddar, "Nonlinear dynamics of a two-stage gear system with mesh stiffness fluctuation, bearing flexibility and backlash," Mechanism and Machine Theory, vol. 44, no. 5, pp. 1058-1069, 2009.

[28] R. Russo, R. Brancati, and E. Rocca, "Experimental investigations about the influence of oil lubricant between teeth on the gear rattle phenomenon," Journal of Sound and Vibration, vol. 321, no. 3-5, pp. 647-661, 2009.

[29] B. K. Han, M. K. Cho, C. Kim, C. H. Lim, and J. J. Kim, "Prediction of vibrating forces on meshing gears for a gear rattle using a new multi-body dynamic model," International Journal of Automotive Technology, vol. 10, no. 4, pp. 469-474, 2009.

[30] G. Chen, "Nonlinear dynamic of unbalance-looseness coupling faults of rotor-ball bearing-stator coupling system," Chinese Journal of Mechanical Engineering, vol. 44, no. 3, pp. 82-88, 2008 . 

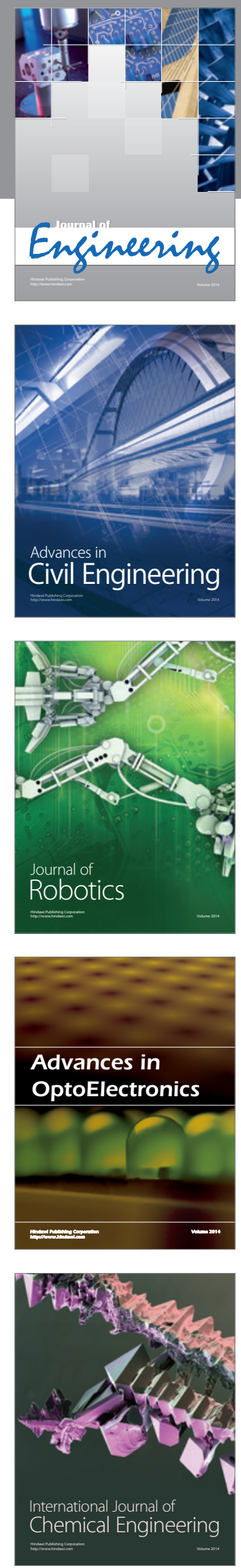

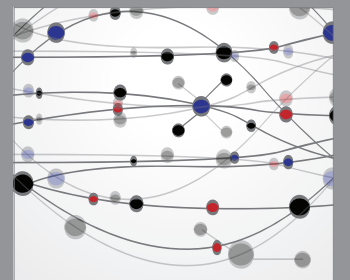

The Scientific World Journal
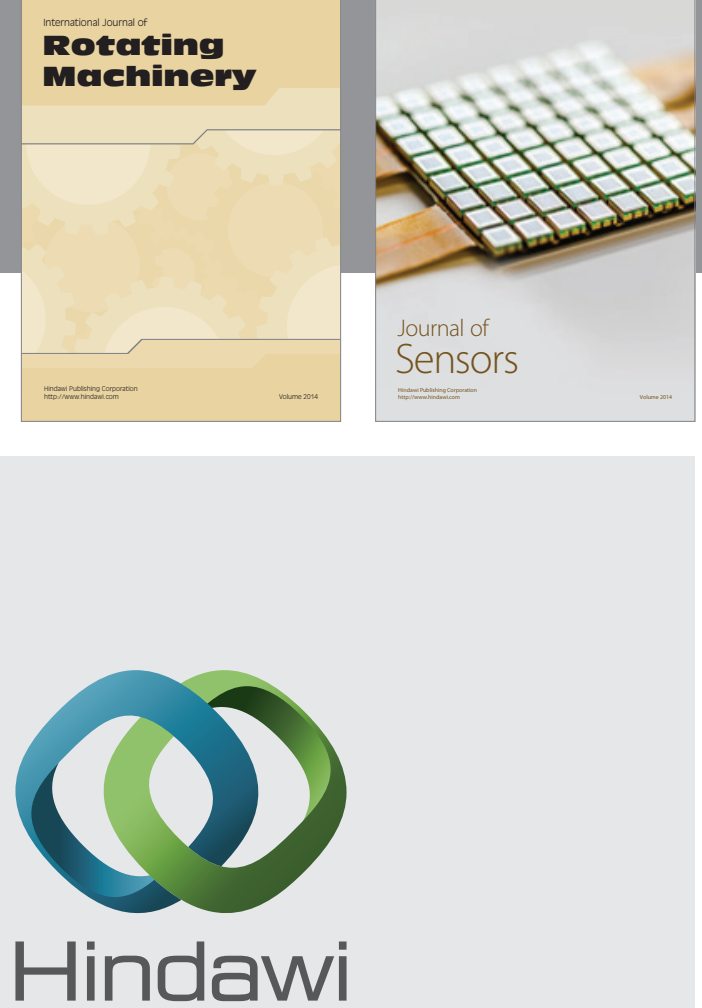

Submit your manuscripts at http://www.hindawi.com
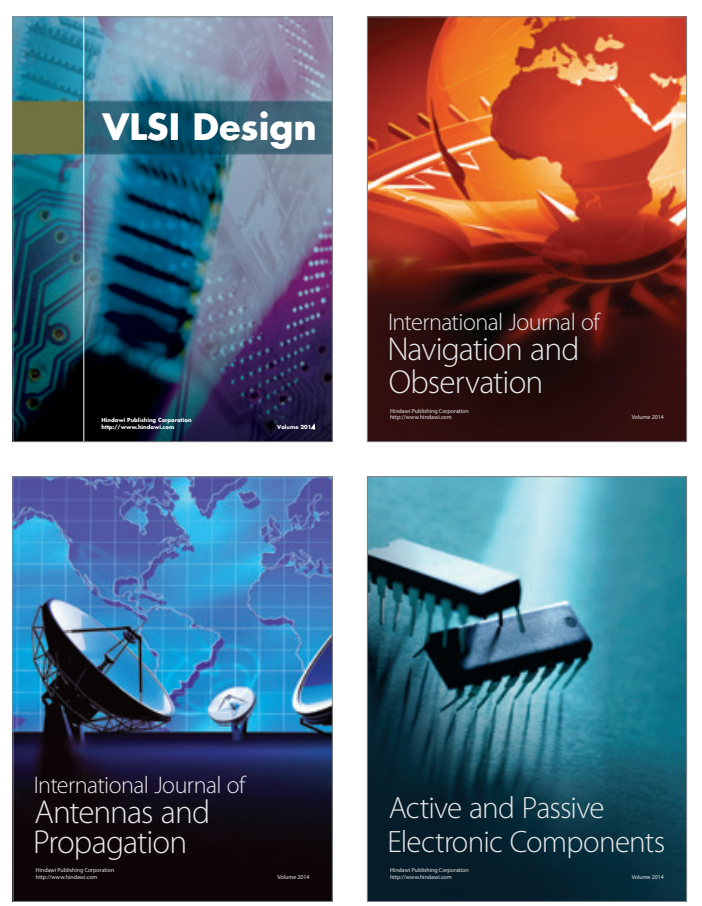
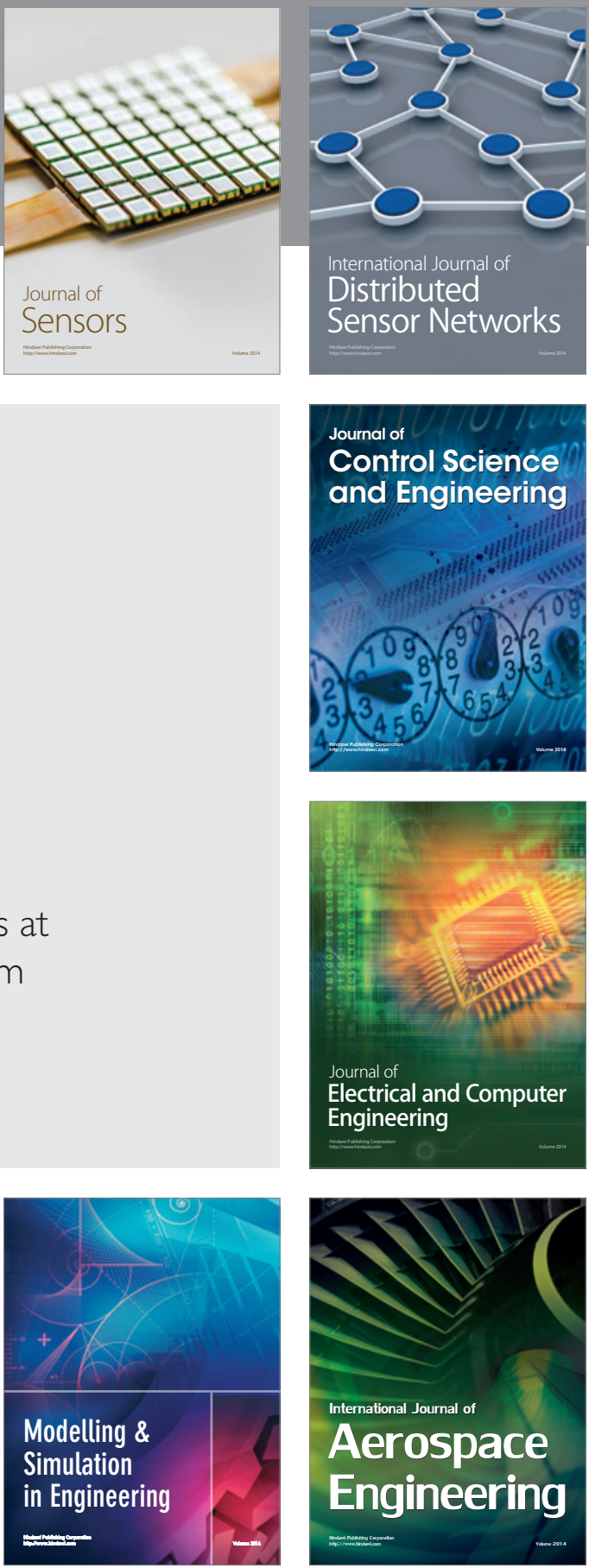

Journal of

Control Science

and Engineering
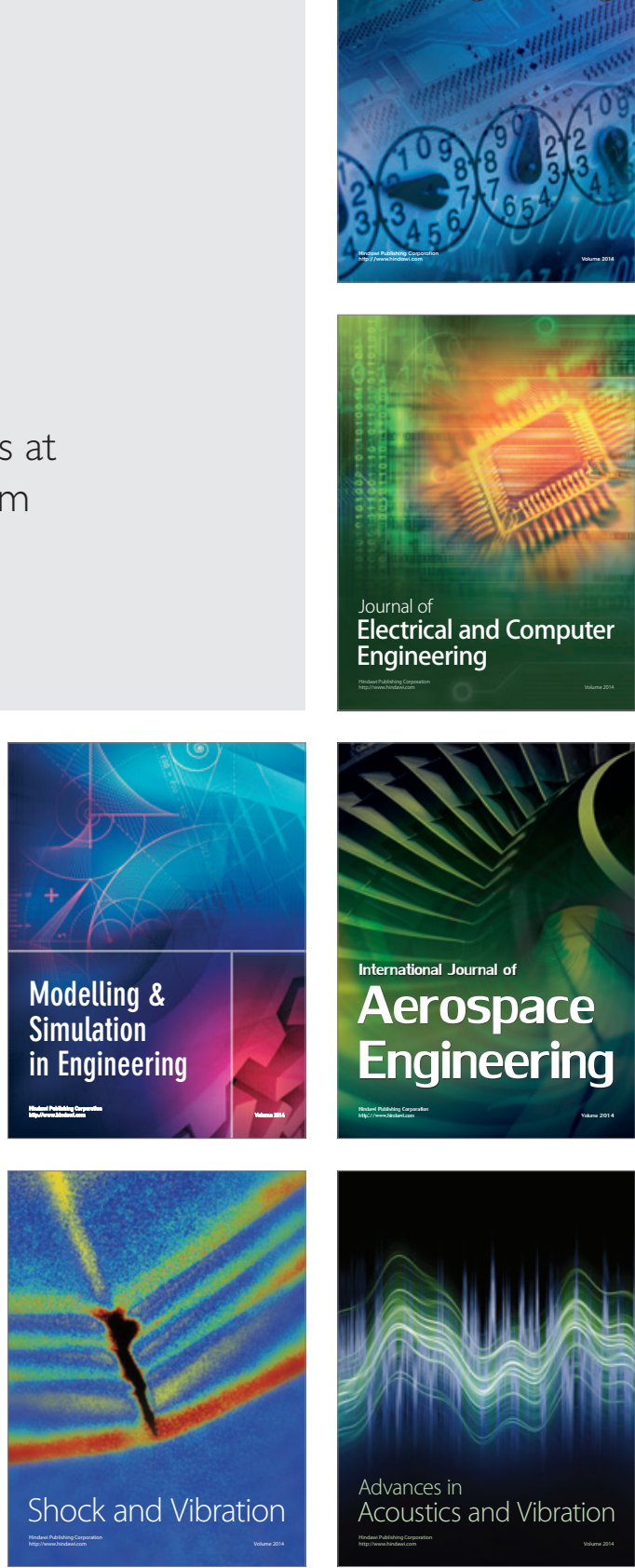